Changes to the Playing Field: A Contemporary Study of Actual Online Sports Betting

\author{
Sarah E. Nelson ${ }^{a, b}$ \\ Timothy C. Edson ${ }^{a, b}$ \\ Eric R. Louderback ${ }^{\text {a }}$ \\ Matthew A. Tom ${ }^{\mathrm{a}, \mathrm{b}}$ \\ Alessandra Grossman ${ }^{a}$ \\ Debi A. LaPlante a, b \\ a Division on Addiction, Cambridge Health Alliance \\ bepartment of Psychiatry, Harvard Medical School
}

Note: This is a pre-print that has yet to complete the peer review process.

Corresponding author: Sarah E. Nelson - snelson@hms.harvard.edu 


\begin{abstract}
Online sports wagering is a popular and still growing gambling activity around the world. Like other types of gambling, it can lead to problems that include devastating financial, social, and healthrelated harms. The first analysis of actual online sports wagering activity (LaBrie, LaPlante, Nelson, Schumann, \& Shaffer, 2007) suggested that levels of financial and time involvement were more moderate than anticipated from earlier survey studies. However, these findings are now more than a decade old. The current study examined actual online sports wagering activity of a similar cohort of 32,262 online gamblers from 2015 to understand how sports betting might have changed in ten years. Measures included subscriber characteristics, betting activities, and transactional activities. Online sports wagering behavior was similar to what was found a decade ago, with the majority of subscribers exhibiting modest to moderate, and a small subset exhibiting disproportionately high engagement, transactional activity, and in-game betting. These findings suggest that further investigation of individual trajectories of sports wagering behavior and engagement with different types of sports wagering products is merited.
\end{abstract}




\section{Changes to the Playing field: A Contemporary Study of Actual Online Sports Betting}

During 2007, LaBrie, LaPlante, Nelson, Schumann, \& Shaffer (2007) published the first comprehensive description of actual online sport gambling behavior among a large population of bwin.party service subscribers. Prior to this publication, research about online gambling only included commentaries and studies that relied upon self-reported online gambling behavior (e.g., Griffiths \& Parke, 2002; Ladd \& Petry, 2002; Mitka, 2001; Petry \& Mallya, 2004). Many such studies identified online gambling as a disproportionately risky type of gambling. In contrast with those earlier studies, LaBrie and colleagues (2007) observed that online sports gambling among new service subscribers was more moderate than might have been expected. Specifically, they found that fixed-odds (i.e., sports gambling propositions that are selected prior to the start of a contest where the odds are set at the time the bet is placed) bettors made about 2.5 bets of 4 euros every fourth day, and most bettors were active for about 4 months, from their first to their last bet. Live action, also known as "in-game" (i.e., sports gambling propositions that can only be selected once a contest begins and whose odds can change throughout the contest) bettors made about 2.8 bets of 4 euros every fourth day, and were active for about 6 weeks from first to last bet. Notably, LaBrie and colleagues (2007) distinguished highly involved subgroups of bettors whose betting activities were discontinuously higher than the remaining $99 \%$ of the sample. Although these findings remain important, the data from this study is now more than ten years old. The current study sought to update our understanding of online sports gambling by assessing the actual gambling behavior of a contemporary sample of online sports gamblers.

\section{Understanding Internet Gambling}

Internet gambling includes a variety of online activities such as casino games, sports betting, backgammon, bingo, and poker. Recent research related to internet gambling continues to highlight its risk potential, but the reality of online gambling is complicated. For example, in Spain, researchers observed an increase in young individuals experiencing gambling disorder during the two years following legalization of internet gambling (Choliz, 2016). Similarly, a national survey of Italian adolescents found problem gambling rates to be five times higher among online gamblers compared to non-online gamblers (Canale, Griffiths, Vieno, Siciliano, \& Molinaro, 2016). In the UK, comparisons of samples of individuals who sought treatment for problem gambling in 2015 and 2002 indicated that significantly more individuals in 2015 reported internet gambling compared to individuals surveyed in 2002 (Sharman, Murphy, Turner, \& Roberts, 2019). Although these findings are suggestive, it is important to 
consider that Gainsbury (2015) concluded from a systematic review of the literature that, "Internet gambling does not cause gambling problems in, and of, itself. However, use of Internet gambling is more common among highly involved gamblers, and for some Internet gamblers, this medium appears to significantly contribute to gambling problems." (pp. 189-190). Further, research suggests that few gamblers readily engage with consumer protection tools online (Gainsbury, Angus, Procter, \& Blaszczynski, 2020). Specifically, Gainsbury and colleagues found that only $24.5 \%$ of online gamblers reported using deposit limits and a very small percentage (8.1\%) reported using time outs. This suggests that more research is needed to better understand the factors that make internet gambling a durable public health concern and gamblers' complex relationship with the medium.

Much research on internet gambling relies upon self-report methodology (Shaffer, Peller, LaPlante, Nelson, \& LaBrie, 2010). However, studies that compare self-reported and actual gambling behavior find important divergence between these sources of information (e.g., Braverman, Tom, \& Shaffer, 2014; Wohl, Davis, \& Hollingshead, 2017), indicating that self-report alone might not be a reliable measure of online gambling activity. Indeed, studies of actual online gambling behavior suggest a more moderate pattern of activity than some self-report studies imply. For example, an analysis of online gamblers in Iceland found that each individual bet an average of three days per month, placed less than two bets each day that they bet and lost an average of $\$ 40$ dollars over a two-year period. Only the top $1 \%$ of bettors placed more than three bets per day (Gray, Jonsson, LaPlante, \& Shaffer, 2015). Similarly, a study of online poker player activity found that only a small group of players engaged heavily (LaPlante, Kleschinsky, LaBrie, Nelson, \& Shaffer, 2009). These findings suggest that the majority of online gamblers only engage at low to moderate levels, with a very small sub-group of users engaging heavily. Nonetheless, given the important clinical observations of shifting gambling habits (e.g., Sharman et al., 2019), more research attention is needed. This might be especially true for sports betting, which as described below, is expanding.

\section{Internet Sports Betting}

As with online gambling more generally, internet sports betting has increased during the last decade as technological advances have been made, including widespread high-speed internet access, ubiquitous smartphone use, and advances in computing power (Lawn et al., 2020). In fact, online sports betting was the most popular form of online gambling in Europe in 2018 (European Gaming and Betting Association, 2019), and opportunities for sports betting have expanded substantially in the U.S. following the Supreme Court ruling in 2018 that removed Federal restrictions on sports wagering (Legal Sports Report, 2020). Researchers also have observed this rise in online sports betting within gambling 
treatment settings, with more gambling treatment seekers than before reporting difficulties controlling their online sports betting (Blaszczynski \& Hunt, 2011).

The nature of online sports betting itself also has been changing. For instance, the addition of new features to online gambling websites potentially make it easier for individuals to keep placing bets. Some of these new features include additional live in-play betting options, cash out features, instant deposits, and micro-betting (Lopez-Gonzalez, Estévez, \& Griffiths, 2019; Winters \& Derevensky, 2019). Such features have important consequences. In a survey of online sports bettors, gamblers felt that online betting is riskier than in-venue sports betting because of the features of online gambling websites (Parke \& Parke, 2019). For example, those surveyed indicated that being able to deposit money instantly into an online account makes it more likely an individual will chase their losses and less likely that individual will take a break from play (Parke \& Parke, 2019). Unfortunately, bettors who have gamblingrelated problems might be more likely to use these novel internet sports betting options. LopezGonzales and colleagues (2019) reported that among individuals who placed at least one bet on sports in the last twelve months, using these new features was related to problem gambling status. Specifically, this study showed that problem gambling was positively associated with how often bets were discussed with others before they were placed, using the cash out feature and other similar features, and spending more time placing bets. It also reported that in-play betting and fantasy sports participation were more common among problem gamblers.

But, as with online gambling more generally, the online sports betting landscape is more varied than it would initially seem. Work investigating daily fantasy sports (DFS), a relatively new, rapid-cycling fantasy sports option, provides some evidence about how populations of subscribers respond to new sports-related offerings. A study looking at DFS players' activity on the DraftKings website during the 2014 football season found that individuals spent a median of $\$ 87$ in entry fees and had a median net loss of $\$ 30.7$. However, there was a small subgroup, $1 \%$ of players, whose engagement was disproportionately higher; they entered more contests, spent more money, and had a greater net loss (Nelson et al., 2019). Additionally, DFS players who scored in the top $1 \%$ on engagement measures increased the amount of time they spent playing over a 27 month period, whereas the remaining $99 \%$ of players showed an initial increase in play and then decreased engagement over time (Edson \& LaPlante, 2020). These findings demonstrate that engagement in online DFS is moderate for the vast majority of players, but potentially extreme among others. The nature of today's online sports betting remains an open question. 


\section{Current Study}

The goal of this paper is to replicate and extend the 2007 study of sports gambling among a large cohort of online gamblers (LaBrie et al., 2007). Given the expansion in online sports gambling and changes in regulations, offerings, and providers since the data for that paper were collected in 2005, the current paper will provide a narrative comparison of that original sample to the overall playing trends of a sample of sports bettors who subscribed to the same provider during 2015 -- ten years later. For this reason, our analyses examine data over an 8-month study period to replicate the study period from the 2007 LaBrie and colleagues paper. In addition to comparing the playing behavior of the more recent sample to the original sample, we also extend the original paper's analysis by examining (a) more detailed information about types of bets placed, and (b) additional information about the transactional patterns (i.e., deposit and withdrawal behavior) of the 2015 sample. Three primary research questions guide this work. Below we list each question and, where applicable, our hypotheses based on prior work:

(1) What are the actual online sports betting behaviors of a contemporary cohort of new subscribers to a European internet sports betting site across an 8-month time period?

(a) Hypothesis 1: The 2015 sample of online sports bettors will exhibit online sports betting behaviors that are on the same order of magnitude as those exhibited by the original 2005 online sports gambling cohort analyzed by LaBrie and colleagues (2007).

(2) What are the transactional patterns (i.e., deposits and withdrawals) of a contemporary cohort of new subscribers to a European internet sports betting site across an 8-month time period?

(a) We do not have specific hypotheses about transactional patterns among our sample because this is an exploratory research question and we are aware of no other work examining these variables among a cohort of online sports bettors.

(3) Among a contemporary cohort of new subscribers to a European internet sports betting site, is it possible to distinguish sub-groups of highly involved sports bettors whose betting and/or losses across 8 months of play are discontinuously high?

(a) Hypothesis 2: We will be able to distinguish subgroups of highly involved sports bettors whose activity across 8 months is discontinuously high.

(b) Hypothesis 3: Approximately 1\% of our sample will exhibit discontinuously high number of bets, $1 \%$ will exhibit discontinuously high amount wagered, and $1 \%$ will exhibit discontinuously high net loss. 
(c) Hypothesis 4: The overlap between these highly involved subgroups will be higher for the net loss and amount wagered subgroups than for the number of bets subgroup with either the net loss or amount wagered subgroup.

(d) Hypothesis 5: Highly involved subgroups will be more likely to place in-game, combo, and system bets ${ }^{1}$ than the less involved subgroups, and will be more likely to be engaged in other types of betting such as playing poker, casino, or bingo.

\section{Method}

\section{Participants}

To use similar procedures to the 2007 study of online sports gambling (LaBrie et al., 2007), we obtained the population of all individuals who subscribed to the bwin online gambling platform between February 1st, 2015 and February 28th, 2015, inclusive. In all, 72,494 individuals subscribed to the bwin online gambling platform during this time. Consistent with LaBrie et al. (2007), we excluded: (a) individuals who did not place a sports bet during the first 7 months of the study period (to allow for at least a month of potential betting activity to inform the betting activity variables) ${ }^{2}$; (b) individuals who did not make a deposit into their accounts during the first 7 months of the study period; and (c) individuals who did not place a sports bet after having deposited money into their accounts within the first 7 months of the study period. These exclusions resulted in a final analytic sample of 32,262 individuals. Figure 1 provides a diagram of the sample.

\section{Figure 1. Sample Diagram.}

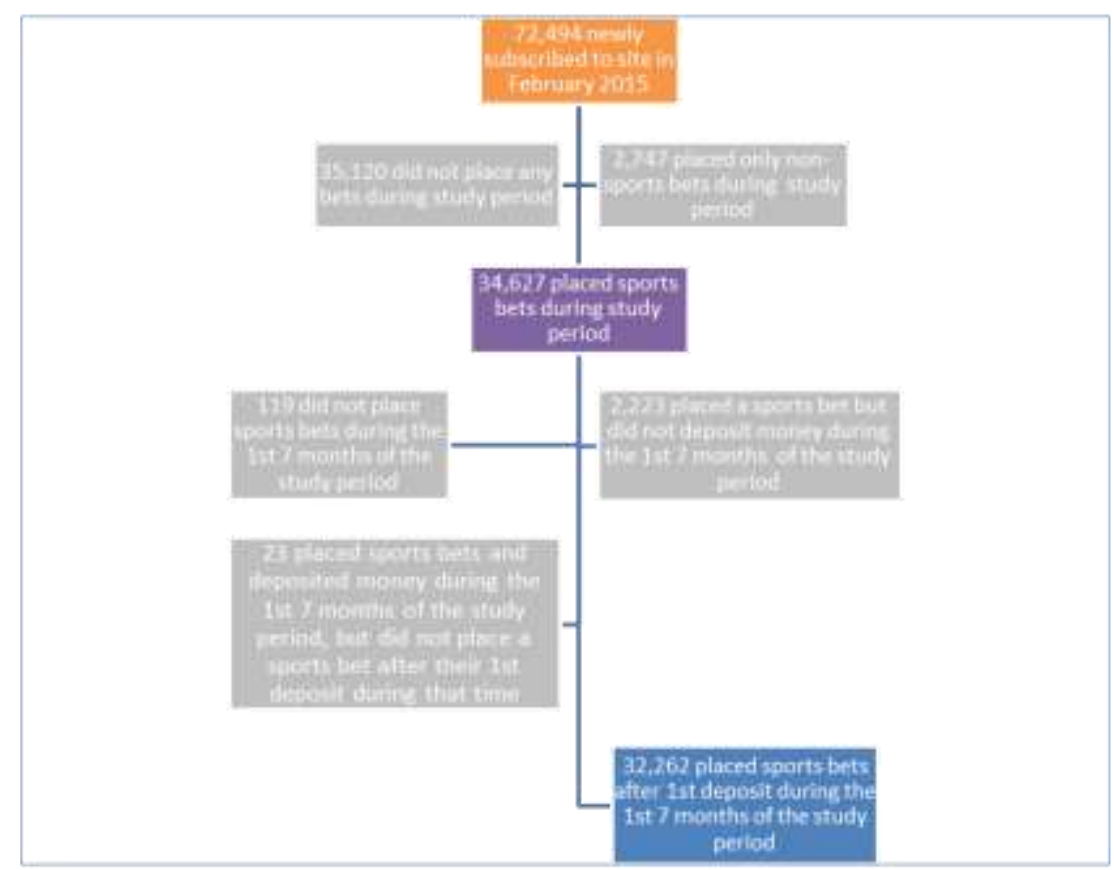




\section{Measures}

This study included variables from four separate data tables provided by GVC (bwin's parent company), covering the time period from February 1st, 2015 through September 30th, 2015: (a) a bettor characteristics file with demographic information and betting snapshot information (e.g., date of registration, date of first bet on different products) about each individual in our sample; (b) a raw sports betting file that includes a row for every sports wager made by each individual in our sample; (c) a deposit file, including all deposit activity for our sample; and (d) a withdrawal file, including all withdrawal activity for our sample. The subsections below detail the variables available in each data table and the variables we created from each file. Table 1 includes definitions for the variables used in the current paper.

Table 1. Variable Definitions.

\begin{tabular}{|c|c|c|}
\hline File & Variable Name & Variable Definition \\
\hline \multirow{5}{*}{$\begin{array}{l}\text { Bettor } \\
\text { Characteristic } \\
\text { File }\end{array}$} & Age & Subscriber's age in years on their initial registration date \\
\hline & Gender & Male or female \\
\hline & Country & The subscriber's country of residence \\
\hline & Country group & $\begin{array}{l}\text { Country of residence; countries } w / \text { less than } 5 \% \text { of the sample labelled as } \\
\text { "other" }\end{array}$ \\
\hline & Number of games played & $\begin{array}{l}\text { Number of game types (i.e., sports, poker, casino) on which the subscriber } \\
\text { placed at least one bet during the study period }\end{array}$ \\
\hline \multirow{14}{*}{$\begin{array}{l}\text { Sports Betting } \\
\text { File }\end{array}$} & Duration & $\begin{array}{l}\text { The difference (in days) between a subscriber's last sports betting day and a } \\
\text { subscriber's first sports betting day, inclusive }\end{array}$ \\
\hline & Frequency & $\begin{array}{l}\text { Percent of days within a subscriber's duration on which the subscriber placed } \\
\text { at least one sports bet }\end{array}$ \\
\hline & Number of bets & Total number of sports bets a subscriber placed \\
\hline & In-game bet percentage & $\begin{array}{l}\text { Percent of a subscriber's sports bets that are in-game bets (i.e., number of in- } \\
\text { game bets divided by total number of bets, multiplied by 100) }\end{array}$ \\
\hline & Combo bet percentage & $\begin{array}{l}\text { Percent of a subscriber's sports bets that are combo bets (i.e., number of } \\
\text { combo bets divided by total number of bets, multiplied by } 100 \text { ) }\end{array}$ \\
\hline & System bet percentage & $\begin{array}{l}\text { Percent of a subscriber's sports bets that are system bets (i.e., number of } \\
\text { system bets divided by total number of bets, multiplied by 100) }\end{array}$ \\
\hline & Bets per betting day & $\begin{array}{l}\text { Total number of sports bets divided by the number of days on which the } \\
\text { subscriber placed at least one sports bet }\end{array}$ \\
\hline & Total wagered & Total amount wagered by a subscriber on sports bets \\
\hline & $\begin{array}{l}\text { In-game percent } \\
\text { wagered }\end{array}$ & $\begin{array}{l}\text { Percent of a subscriber's total wagered on sports bets that is wagered on in- } \\
\text { game bets (i.e., amount wagered on in-game bets divided by total amount } \\
\text { wagered on sports bets, multiplied by 100) }\end{array}$ \\
\hline & Combo percent wagered & $\begin{array}{l}\text { Percent of a subscriber's total wagered on sports bets that is wagered on } \\
\text { combo bets (i.e., amount wagered on combo bets divided by total amount } \\
\text { wagered on sports bets, multiplied by 100) }\end{array}$ \\
\hline & $\begin{array}{l}\text { System bet percent } \\
\text { wagered }\end{array}$ & $\begin{array}{l}\text { Percent of a subscriber's total wagered on sports bets that is wagered on } \\
\text { system bets (i.e., amount wagered on system bets divided by total amount } \\
\text { wagered on sports bets, multiplied by 100) }\end{array}$ \\
\hline & Average bet size & $\begin{array}{l}\text { Total wagered on sports bets divided by the total number of sports bets } \\
\text { placed }\end{array}$ \\
\hline & Net loss & Total amount wagered on sports bets minus the total winnings on sports bets \\
\hline & Percent lost & $\begin{array}{l}\text { Net loss on sports bets divided by total amount wagered on sports bets, } \\
\text { multiplied by } 100\end{array}$ \\
\hline
\end{tabular}


Table 1. (cont.)

\begin{tabular}{|c|c|c|}
\hline File & Variable Name & Variable Definition \\
\hline \multirow{9}{*}{$\begin{array}{l}\text { Deposit Activity } \\
\text { File }\end{array}$} & Total deposit amount & Sum of amount successfully deposited \\
\hline & Number of deposits & Number of deposits denoted as completed \\
\hline & Number of deposit days & Number of days on which the subscriber made a completed deposit \\
\hline & $\begin{array}{l}\text { Deposits per deposit } \\
\text { day }\end{array}$ & $\begin{array}{l}\text { Number of completed deposits divided by number of days on which the } \\
\text { subscriber made a completed deposit }\end{array}$ \\
\hline & $\begin{array}{l}\text { Average deposit } \\
\text { amount }\end{array}$ & $\begin{array}{l}\text { Sum of amount successfully deposited divided by number of completed } \\
\text { deposits }\end{array}$ \\
\hline & $\begin{array}{l}\text { Number of failed } \\
\text { deposits }\end{array}$ & Number of deposits denoted as failed \\
\hline & Percent failed deposits & $\begin{array}{l}\text { Number of deposits denoted as failed divided by total number of attempted } \\
\text { deposits, multiplied by } 100\end{array}$ \\
\hline & $\begin{array}{l}\text { Number of unique } \\
\text { payment methods }\end{array}$ & $\begin{array}{l}\text { Count of unique value combinations for deposit payment method and deposit } \\
\text { payment type }\end{array}$ \\
\hline & $\begin{array}{l}\text { Number of unique } \\
\text { credit cards }\end{array}$ & $\begin{array}{l}\text { Count of unique values for deposit payment method that correspond to credit } \\
\text { card payment type }\end{array}$ \\
\hline \multirow{7}{*}{$\begin{array}{l}\text { Withdrawal } \\
\text { Activity File }\end{array}$} & $\begin{array}{l}\text { Total withdrawal } \\
\text { amount }\end{array}$ & Sum of amount successfully withdrawn \\
\hline & Number of withdrawals & Number of withdrawals denoted as completed \\
\hline & $\begin{array}{l}\text { Number of withdrawal } \\
\text { days }\end{array}$ & Number of days on which the subscriber made a completed withdrawal \\
\hline & $\begin{array}{l}\text { Withdrawals per } \\
\text { withdrawal day }\end{array}$ & $\begin{array}{l}\text { Number of completed withdrawals divided by number of days on which the } \\
\text { subscriber made a completed withdrawal }\end{array}$ \\
\hline & $\begin{array}{l}\text { Average withdrawal } \\
\text { amount }\end{array}$ & $\begin{array}{l}\text { Sum of amount successfully withdrawn divided by number of completed } \\
\text { withdrawals }\end{array}$ \\
\hline & $\begin{array}{l}\text { Number of reversed } \\
\text { withdrawals }\end{array}$ & Number of withdrawals denoted as reversed \\
\hline & $\begin{array}{l}\text { Percent reversed } \\
\text { withdrawals }\end{array}$ & $\begin{array}{l}\text { Number of withdrawals denoted as reversed divided by total number of } \\
\text { attempted withdrawals, multiplied by } 100\end{array}$ \\
\hline
\end{tabular}

Bettor Characteristics File. The individual-level variables available for the sample included gender, age, and country, as well as date of registration (i.e., the date the bettor opened an account on bwin), date of first deposit, and date of first play on each game type. From these variables, we also created two transformed variables. For the first transformed variable, country group, we followed LaBrie et al.'s (2008) method for coding country groups. This involved coding individual countries as their own category if they comprised at least $5 \%$ of the sample, and coding them within an "other countries" group if they comprised less than $5 \%$ of the sample. For the second transformed variable, the number of games played, we used the "first played" dates in the bettor characteristics file to sum the different types of gambling that a subscriber had played. Scores ranged from ' 1 ' (for individuals who only placed sports bets) to ' 3 ' (for individuals who placed sports bets, played poker, and played casino games).

Sports Betting File. The sports betting file included details about each sports bet placed by individuals in our sample during the study period, detailing the type of sports wager, date placed, date resolved, stakes, and winnings. Type of sports wager indicated whether the bet was a single pre-match bet, a single in-game bet (i.e., a bet placed after a game has already begun), a combo bet (i.e., a 
combination of single pre-match and/or in-game bets, all of which have to be correct in order to win), or part of a system bet (i.e., a combination of single and/or combo pre-match and/or in-game bets, only some of which have to be correct to win) $)^{3}$. For combo bets, the file also included information about whether the individual paid for bet protection ${ }^{4}$. We used these variables to create the following transformed variables for each individual, as defined in Table 1: duration, frequency, number of bets, ingame bet percentage, combo bet percentage, system bet percentage, bets per betting day, total wagered, in-game percent wagered, combo percent wagered, system percent wagered, average bet size, net loss, and percent lost. For total wagered and net loss, we included bet protection in our calculations. All currencies are in euros.

Deposit Activity File. The deposit activity file included five measured variables about every deposit made by individuals in our sample during the study period, including deposit date (i.e., date on which deposit was placed), deposit payment method (e.g., Visa, PayPal), deposit payment type (e.g., credit card, debit card), deposit amount, and deposit status (i.e., whether the deposit was completed or failed). From these variables, we created the following transformed variables, defined in Table 1: total deposit amount, number of deposits, number of deposit days, deposits per deposit day, average deposit amount, number of failed deposits, percent failed deposits, number of unique payment methods, number of unique credit cards.

Withdrawal Activity File. The withdrawal activity file included three measured variables about every withdrawal made by individuals in our sample during the study period, including withdrawal date (i.e., date on which the withdrawal was made), withdrawal amount, and withdrawal status (i.e., whether the withdrawal was completed or reversed). From these variables, we created the following transformed variables, defined in Table 1: total withdrawal amount, number of withdrawals, number of withdrawal days, withdrawals per withdrawal day, average withdrawal amount, number of reversed withdrawals, and percent reversed withdrawals.

\section{Procedure}

During 2016, the original provider of LaBrie et al.'s (2007) online sports gambling data, bwin, was acquired by the European online gambling operator, GVC Holdings, PLC (GVC). The 2015 sample therefore came from the data warehouse of bwin records now maintained by GVC. We worked with GVC, to obtain 8 months of betting activity and transactional records for all individuals who subscribed to bwin in February 2015. As noted in the Participants section, we constrained the sample to include only those who deposited their own money to ensure that individuals were not gambling only with promotional funds from bwin. For the same reason, we required that the individuals' gambling activity 
include sports betting after having deposited their own money. We required that this betting activity commence within the first 7 months of the study period to ensure that subscribers have at least one month of potential betting activity after their first sports bet to be included in the 8-month aggregates we calculated for the study.

The Cambridge Health Alliance Institutional Review Board evaluated our study plans and confirmed that the study did not qualify as human subjects research because all data were de-identified. We preregistered this study on the Open Science Framework (https://osf.io/2356v/?view only=7a058166e91f437f8c269fa066b1802a).

\section{Analytic Plan}

Consistent with LaBrie et al. (2007), and because we conducted multiple comparisons and had a large sample size, we used a significance level of $\alpha=0.001$ as our criterion for statistically significant results. All reported $p$-values reflect two-tailed tests of significance. Because the distributions of many of the variables are skewed, when reporting results in the text, we provide medians as our measures of central tendency.

Research Question 1. Our first research question, investigating the betting activity of subscribers in the sample, involved descriptive analyses. For all numerical bettor characteristic and betting activity variables (i.e., all variables from the sports betting file, as well as age and number of game types from the player characteristics file, listed in Table 1), we provided a five-number summary (minimum, lower quartile, median, upper quartile, maximum), mean, and standard deviation. For all categorical variables (i.e., gender, country group, and the proportion of the sample that engages in different types of betting), we provided counts and percentages. We also examined correlations between betting variables using Spearman's $\rho$. These analyses were pre-registered and addressed Hypothesis 1, examining whether betting activity differed substantially from the activity observed a decade ago by LaBrie et al. (2007).

To examine whether betting activity differed by gender, we employed Mann-Whitney $U$ tests; to examine whether these variables differed by age, we conducted correlation analyses using Spearman's $\rho$. We used these techniques (i.e., Spearman's $\rho$ and Mann-Whitney $U$ tests) to account for the anticipated skew in our variables. These analyses by gender and age were pre-registered, but we did not have specific hypotheses about them.

Research Question 2. Our second research question, investigating the transactional activity of subscribers in the sample, also involved descriptive analyses. For all numerical transactional activity variables (i.e., all variables from the deposit and withdrawal activity files, listed in Table 1), we provided 
a five-number summary (minimum, lower quartile, median, upper quartile, maximum), mean, and standard deviation. For all categorical variables (i.e., the proportion of the sample that places any failed deposits, or reverses any withdrawals), we provided counts and percentages. We also examined correlations between deposit variables and correlations between withdrawal variables using Spearman's $\rho$. To examine whether deposit or withdrawal activity differed by gender, we employed Mann-Whitney $U$ tests; to examine whether these variables differed by age, we conducted correlation analyses using Spearman's $\rho$. These analyses were pre-registered, but we did not have specific hypotheses about them.

Research Question 3. To investigate the presence of highly involved subgroups with disproportionate levels of betting activity (i.e., Research Question 3), we replicated the methods used by LaBrie and colleagues (2007). We created centile plots for total wagered, net loss, and number of bets. Similar to examination of a scree plot in factor analysis, we visually inspected these plots to determine whether there was discontinuity in the top percentiles compared to the rest of the plot. We identified the point of discontinuity for each plot and created groups of highly involved sports bettors for each of those variables based on that point of discontinuity. These pre-registered analyses addressed Hypotheses 2 and 3.

We examined overlap between these groups (e.g., the number of subscribers who belong to both total wagered and net loss highly involved subgroups, the number of subscribers who belong to both total wagered and number of bets highly involved subgroups, etc.) using Fisher's exact tests to determine whether there were differences in overlap between each group pairing. Although both Fisher's and Chi-Square tests usually yield comparable statistics, we opted for Fisher's tests because of their ability to handle any low expected cell counts we encounter. We employed Mann-Whitney $U$ tests for comparing age, number of games played, and all betting behavior and transactional activity variables between each highly involved subgroup and the rest of the sample. We also compared gender, country group, the number of individuals with failed deposits, the number of individuals with reversed withdrawals, the number of individuals who placed bets on games other than sports, and the number of individuals who placed in-game, combo, and system bets between the highly involved subgroups and the rest of the sample using Fisher's exact tests. These pre-registered analyses addressed Hypothesis 5.

Unregistered analyses. We conducted one additional set of analyses that we did not preregister, based on examination of the data. When examining centile plots to create the highly involved subgroups, we noticed that there was a group that was disproportionately low on net loss, in addition to the disproportionately high group. Therefore, we created a fourth highly involved group (i.e., high net winners). We compared that group to the other highly involved groups in terms of overlap (using 
Fisher's exact tests), and also compared it to individuals who did not belong to any of the highly involved group on betting, withdrawal, and deposit activity.

\section{Results}

\section{Bettor Characteristics}

Among the 32,262 subscribers in our sample, $90.6 \%$ were male with a median age of 27

$(M=30.1 ; S D=10.3 ; M i n=14$; lower quartile $[L Q]=22$; upper quartile $[U Q]=35 ; M a x=95)$. Almost one third (32.1\%) were from Germany, $16.8 \%$ were from Spain, $15.1 \%$ were from the United Kingdom, and $11.4 \%$ were from France. The remaining quarter (24.8\%) resided in a country that comprised less than $5 \%$ of the sample.

\section{Betting Activity - Research Question 1}

Table 2 provides information about the sports betting behavior of our sample during the 8month study period.

Table 2. Sports Betting Activity $\left(N=32,262^{\mathrm{a}}\right)$

\begin{tabular}{|l|l|l|l|l|l|l|l|}
\hline Variable & Mean & SD & Min & $\begin{array}{l}\text { Lower } \\
\text { quartile }\end{array}$ & Median & $\begin{array}{l}\text { Upper } \\
\text { quartile }\end{array}$ & Max \\
\hline Duration & 62.24 & 79.12 & 1.00 & 3.00 & 19.00 & 98.00 & 242.00 \\
\hline Frequency & 53.06 & 36.65 & 1.00 & 18.18 & 45.70 & 100.00 & 100.00 \\
\hline \# of Bets & 92.80 & 374.12 & 1.00 & 4.00 & 15.00 & 62.00 & $16,406.00$ \\
\hline In-game Bet \% & 31.18 & 35.20 & 0.00 & 0.00 & 16.38 & 57.14 & 100.00 \\
\hline Combo Bet \% & 36.64 & 36.65 & 0.00 & 0.00 & 25.62 & 68.57 & 100.00 \\
\hline System Bet \% & 4.65 & 16.49 & 0.00 & 0.00 & 0.00 & 0.00 & 100.00 \\
\hline Bets per Betting Day & 4.37 & 6.74 & 1.00 & 1.43 & 2.50 & 4.67 & 223.30 \\
\hline \# of Games Played & 1.29 & 0.54 & 1.00 & 1.00 & 1.00 & 2.00 & 3.00 \\
\hline Total Wagered & $1,093.86$ & 7361.54 & 0.00 & 30.00 & 100.00 & 355.02 & $404,422.55$ \\
\hline In-Game \% Wagered & 31.16 & 35.70 & 0.00 & 0.00 & 14.98 & 57.81 & 100.00 \\
\hline Combo \% Wagered & 36.52 & 36.87 & 0.00 & 0.00 & 25.03 & 68.96 & 100.00 \\
\hline System \% Wagered & 2.89 & 12.02 & 0.00 & 0.00 & 0.00 & 0.00 & 100.00 \\
\hline Average Bet Size & 18.30 & 42.04 & 0.00 & 2.68 & 6.10 & 14.20 & $1,930.87$ \\
\hline Net Loss & 71.44 & 590.90 & $-12,340.00$ & 7.41 & 25.00 & 85.59 & $31,282.82$ \\
\hline$\%$ Lost & 33.72 & 110.27 & $-12,130.00$ & 7.74 & 35.83 & 92.57 & 100.00 \\
\hline
\end{tabular}

${ }^{a}$ For 13 bettors, none of their bets had yet resolved, so they are not included in the descriptives for net loss or percent lost. For these two variables, the sample size is $n=32,249$.

Subscribers in our sample had a median 19 days between their first and last bet within the study period, inclusive. They placed bets on a median $46 \%$ of the days within their duration active, and placed a median of 15 bets total, for a median 2.5 bets per active betting day. For a median subscriber, $16 \%$ of their bets were in-game bets, and $26 \%$ were combo bets. The median subscriber did not place any system bets. Overall, $15 \%$ of subscribers placed only single pre-match bets, $65.5 \%$ placed at least one in- 
game bet, $69.8 \%$ placed at least one combo bet, and $11.9 \%$ placed at least one system bet. Three quarters of subscribers (74.7\%) only bet on sports (as opposed to betting on online casino games or playing poker) during the study period; the remaining $25.3 \%$ also participated in one or both of these other forms of gambling. Considering financial involvement, subscribers in our sample wagered a median total of 100 euros during the study period, with a median bet size of 6.1 euros and a median total net loss of 25.0 euros. The median percent lost was $36 \%$. The distribution of the amount of money spent on each type of bet was similar to the distribution of the number of bets: $15 \%$ of money wagered was on in-game bets, $25 \%$ was on combo bets, and $0 \%$ was on system bets.

Table 3 includes information about the correlations between these sports betting variables. Most measures of financial and time involvement were significantly positively related. Exceptions included frequency, which was negatively correlated with most measures of involvement. Number of bets was also negatively correlated with average bet size.

\section{Deposit and Withdrawal Activity - Research Question 2}

Table 4 provides information about the transactional activity of our sample during the 8-month study period. Subscribers in our sample deposited a median of 50 euros and made 2 deposits during the study period. Median average deposit amount was 20 euros, and the median subscriber used only one payment method and no credit cards for their deposits, and had no failed deposits. Only $29.5 \%$ of

subscribers had any withdrawal activity during the study period. Among those who made withdrawals, subscribers withdrew a median 125 euros and made one withdrawal during the study period. Among those who made withdrawals, median average withdrawal amount was 81.3 euros, and the majority of subscribers had no reversed withdrawals. Overall, $42.5 \%$ of subscribers had at least one failed deposit, and $14.7 \%$ who made withdrawals reversed at least one withdrawal.

Table 5 includes information about the correlations between these transactional variables. Deposit and withdrawal behavior tended to be correlated, as did the number and amount of deposits and withdrawals. 
Table 3. Spearman Correlations between Betting Behaviors $\left(N=32,262^{\mathrm{a}}\right)$

\begin{tabular}{|c|c|c|c|c|c|c|c|c|c|c|c|c|c|c|c|}
\hline Variable & Dur & Freq & $\begin{array}{l}\text { \# of } \\
\text { Bets }\end{array}$ & $\begin{array}{l}\text { In- } \\
\text { Game } \\
\text { Bet \% }\end{array}$ & $\begin{array}{l}\text { Combo } \\
\text { Bet \% }\end{array}$ & $\begin{array}{l}\text { System } \\
\text { Bet \% }\end{array}$ & $\begin{array}{l}\text { Bets/ } \\
\text { Day }\end{array}$ & $\begin{array}{l}\text { Tot } \\
\text { Wag }\end{array}$ & $\begin{array}{l}\text { In- } \\
\text { Game \% } \\
\text { Wag }\end{array}$ & $\begin{array}{l}\text { Combo } \\
\% \text { Wag }\end{array}$ & $\begin{array}{l}\text { System } \\
\% \text { Wag }\end{array}$ & $\begin{array}{l}\text { Avg } \\
\text { Bet } \\
\text { Size }\end{array}$ & $\begin{array}{l}\text { Net } \\
\text { Loss }\end{array}$ & $\begin{array}{l}\% \\
\text { Lost }\end{array}$ & $\begin{array}{l}\text { \# of } \\
\text { Games }\end{array}$ \\
\hline Duration & -- & -0.82 & 0.76 & 0.18 & 0.21 & 0.23 & 0.27 & 0.58 & 0.18 & 0.22 & 0.23 & -0.26 & 0.28 & -0.28 & 0.13 \\
\hline Frequency & & -- & -0.40 & -0.05 & -0.16 & -0.11 & -0.06 & -0.28 & -0.05 & -0.16 & -0.11 & 0.17 & -0.17 & 0.10 & -0.11 \\
\hline \# of Bets & & & -- & 0.40 & 0.15 & 0.35 & 0.74 & 0.74 & 0.42 & 0.16 & 0.35 & -0.37 & 0.32 & -0.40 & 0.15 \\
\hline $\begin{array}{l}\text { In-game Bet } \\
\%\end{array}$ & & & & -- & -0.14 & $-0.01^{*}$ & 0.49 & 0.34 & 0.99 & -0.14 & $-0.01^{*}$ & -0.08 & 0.11 & -0.21 & 0.13 \\
\hline Combo Bet \% & & & & & -- & $0.00 *$ & $-0.01 *$ & -0.02 & -0.13 & 0.98 & $0.00 *$ & -0.23 & 0.14 & 0.21 & 0.12 \\
\hline System Bet \% & & & & & & -- & 0.32 & 0.20 & 0.02 & 0.06 & 1.00 & -0.24 & 0.16 & -0.07 & 0.08 \\
\hline $\begin{array}{l}\text { Bets per } \\
\text { Betting Day }\end{array}$ & & & & & & & -- & 0.50 & 0.51 & $0.01 *$ & 0.32 & -0.33 & 0.23 & -0.25 & 0.15 \\
\hline $\begin{array}{l}\text { Total } \\
\text { Wagered }\end{array}$ & & & & & & & & -- & 0.35 & $-0.02 *$ & 0.20 & 0.30 & 0.44 & -0.45 & 0.05 \\
\hline $\begin{array}{l}\text { In-Game \% } \\
\text { Wagered }\end{array}$ & & & & & & & & & -- & -0.14 & 0.02 & -0.09 & 0.12 & -0.21 & 0.13 \\
\hline $\begin{array}{l}\text { Combo \% } \\
\text { Wagered }\end{array}$ & & & & & & & & & & -- & 0.06 & -0.25 & 0.15 & 0.22 & 0.13 \\
\hline $\begin{array}{l}\text { System \% } \\
\text { Wagered }\end{array}$ & & & & & & & & & & & -- & -0.24 & 0.16 & -0.06 & 0.08 \\
\hline $\begin{array}{l}\text { Average Bet } \\
\text { Size }\end{array}$ & & & & & & & & & & & & -- & 0.12 & -0.08 & -0.15 \\
\hline Net Loss & & & & & & & & & & & & & -- & 0.40 & 0.02 \\
\hline \% Lost & & & & & & & & & & & & & & -- & -0.04 \\
\hline $\begin{array}{l}\text { \# of Games } \\
\text { Played }\end{array}$ & & & & & & & & & & & & & & & -- \\
\hline
\end{tabular}

a For 13 bettors, none of their bets had yet resolved, so they are not included in the correlations with net loss or percent lost - n=32,249 for correlations with these two variables. *Spearman correlations that are not significant at $p<0.001$ are flagged. 
Table 4. Transactional Activity ( $\mathrm{N}=32,262$ for deposit variables; $\mathrm{N}=9,529$ for withdrawal variables)

\begin{tabular}{|c|c|c|c|c|c|c|c|}
\hline Variable & Mean & SD & Min & $\begin{array}{l}\text { Lower } \\
\text { quartile }\end{array}$ & Median & $\begin{array}{l}\text { Upper } \\
\text { quartile }\end{array}$ & Max \\
\hline Total Deposit ${ }^{a}$ Amount & 266.15 & $1,216.16$ & 3.66 & 20.00 & 50.00 & 130.00 & $50,315.00$ \\
\hline \# of Deposits & 6.02 & 16.54 & 1.00 & 1.00 & 2.00 & 4.00 & 502.00 \\
\hline \# of Deposit Days & 4.54 & 9.35 & 1.00 & 1.00 & 2.00 & 4.00 & 202.00 \\
\hline $\begin{array}{l}\text { Deposits per Deposit } \\
\text { Day }\end{array}$ & 1.14 & 0.46 & 1.00 & 1.00 & 1.00 & 1.00 & 22.00 \\
\hline $\begin{array}{l}\text { Average Deposit } \\
\text { Amount }\end{array}$ & 42.20 & 91.08 & 2.80 & 12.00 & 20.00 & 43.88 & 5000.00 \\
\hline \# of Failed Deposits & 2.35 & 9.03 & 0.00 & 0.00 & 0.00 & 2.00 & 383.00 \\
\hline$\%$ Failed Deposits & 17.52 & 24.97 & 0.00 & 0.00 & 0.00 & 33.33 & 99.00 \\
\hline \# of Payment Methods & 1.27 & 0.62 & 1.00 & 1.00 & 1.00 & 1.00 & 10.00 \\
\hline $\begin{array}{l}\text { \# of Unique Credit } \\
\text { Cards }\end{array}$ & 0.25 & 0.46 & 0.00 & 0.00 & 0.00 & 0.00 & 3.00 \\
\hline $\begin{array}{l}\text { Total Withdrawal } \\
\text { Amount }\end{array}$ & 495.27 & 1454.24 & 0.00 & 40.44 & 125.00 & 375.00 & $37,889.25$ \\
\hline \# of Withdrawals & 2.44 & 4.90 & 0.00 & 1.00 & 1.00 & 2.00 & 151.00 \\
\hline \# of Withdrawal Days & 2.19 & 3.59 & 0.00 & 1.00 & 1.00 & 2.00 & 82.00 \\
\hline $\begin{array}{l}\text { Withdrawals per } \\
\text { Withdrawal Day }\end{array}$ & 1.02 & 0.39 & 0.00 & 1.00 & 1.00 & 1.00 & 19.00 \\
\hline $\begin{array}{l}\text { Average Withdrawal } \\
\text { Amount }\end{array}$ & 199.66 & 433.04 & 0.00 & 30.00 & 81.33 & 200.00 & 13575.60 \\
\hline $\begin{array}{l}\text { \# of Reversed } \\
\text { Withdrawals }\end{array}$ & 0.47 & 3.82 & 0.00 & 0.00 & 0.00 & 0.00 & 294.00 \\
\hline $\begin{array}{l}\text { \% Reversed } \\
\text { Withdrawals }\end{array}$ & 7.83 & 22.29 & 0.00 & 0.00 & 0.00 & 0.00 & 100.00 \\
\hline
\end{tabular}

a Unless stated otherwise, references to deposits and withdrawals indicate completed deposits and withdrawals (as opposed to including those that failed or were reversed).

\section{Subscriber Activity by Gender and Age - Research Questions 1 \& 2}

In planned exploratory analyses, we examined whether subscribers' betting, deposit, or withdrawal activity differed by age or gender, using Spearman correlations and Mann-Whitney $U$ tests, respectively. We found significant Spearman correlations $(p<0.001)$ between age and eleven of the betting activity variables, between age and eight of the deposit activity variables, and between age and two of the withdrawal activity variables. Overall, older subscribers demonstrated higher engagement and transactional activity than younger subscribers, but effect sizes were small. Nine betting activity variables, five deposit activity variables, and two withdrawal activity variables differed significantly $(p<$ 0.001 ) by gender. Overall, findings were mixed for gender, with men having higher scores on some betting and transactional activity measures and women having higher scores on others. Effect sizes, as assessed by $r$, the standardized test statistic divided by the square root of $\mathrm{N}$, were small, ranging from 0.02 to 0.08 . More detail about the results of these analyses is provided in a Supplementary file, attached at the end of this manuscript. 
Table 5. Spearman Correlations between Transactional Behaviors ( $\mathrm{N}=32,262$ for deposit variables; $\mathrm{N}=9,529$ for withdrawal variables)

\begin{tabular}{|c|c|c|c|c|c|c|c|c|c|c|c|c|c|c|c|c|}
\hline Variable & $\begin{array}{l}\text { Dep } \\
\text { Amt }\end{array}$ & \# Dep & $\begin{array}{l}\text { \# Dep } \\
\text { Days }\end{array}$ & $\begin{array}{l}\text { Dep } \\
\text { per } \\
\text { Dep } \\
\text { Day }\end{array}$ & $\begin{array}{l}\text { Avg } \\
\text { Dep } \\
\text { Amt }\end{array}$ & $\begin{array}{l}\# \\
\text { Failed } \\
\text { Dep }\end{array}$ & $\begin{array}{l}\% \\
\text { Failed } \\
\text { Dep }\end{array}$ & $\begin{array}{l}\# \\
\text { Pymt } \\
\text { Meth }\end{array}$ & $\begin{array}{l}\# \\
\text { Credit } \\
\text { Cards }\end{array}$ & $\begin{array}{l}\text { Wthd } \\
\text { Amt }\end{array}$ & $\begin{array}{l}\# \\
\text { Withd }\end{array}$ & $\begin{array}{l}\# \\
\text { Withd } \\
\text { Days }\end{array}$ & $\begin{array}{l}\text { Withd } \\
\text { per } \\
\text { Withd } \\
\text { Day }\end{array}$ & $\begin{array}{l}\text { Avg } \\
\text { Withd } \\
\text { Amt }\end{array}$ & $\begin{array}{l}\# \\
\text { Rvsd } \\
\text { Dep }\end{array}$ & $\begin{array}{l}\% \\
\text { Rvsd } \\
\text { Dep }\end{array}$ \\
\hline $\begin{array}{l}\text { Total Dep } \\
\text { Amt }\end{array}$ & -- & 0.75 & 0.71 & 0.53 & 0.69 & 0.37 & 0.20 & 0.28 & 0.13 & 0.65 & 0.44 & 0.44 & 0.19 & 0.50 & 0.29 & 0.27 \\
\hline \# Deposits & & -- & 0.97 & 0.61 & 0.09 & 0.49 & 0.28 & 0.34 & 0.05 & 0.38 & 0.47 & 0.47 & 0.18 & 0.18 & 0.29 & 0.27 \\
\hline \# Dep Days & & & -- & 0.45 & 0.07 & 0.49 & 0.28 & 0.34 & 0.05 & 0.35 & 0.48 & 0.49 & 0.17 & 0.15 & 0.27 & 0.25 \\
\hline $\begin{array}{l}\text { Dep per } \\
\text { Dep Day }\end{array}$ & & & & -- & 0.16 & 0.34 & 0.17 & 0.24 & 0.02 & 0.32 & 0.29 & 0.28 & 0.17 & 0.20 & 0.29 & 0.27 \\
\hline $\begin{array}{l}\text { Avg Dep } \\
\text { Amt }\end{array}$ & & & & & -- & 0.03 & $-0.00 *$ & 0.06 & 0.16 & 0.56 & 0.12 & 0.11 & 0.07 & 0.60 & 0.09 & 0.08 \\
\hline $\begin{array}{l}\text { \# Failed } \\
\text { Deposits }\end{array}$ & & & & & & -- & 0.94 & 0.51 & 0.12 & 0.24 & 0.32 & 0.33 & 0.11 & 0.10 & 0.27 & 0.25 \\
\hline $\begin{array}{l}\text { \% Failed } \\
\text { Deposits }\end{array}$ & & & & & & & -- & 0.45 & 0.10 & 0.12 & 0.17 & 0.18 & 0.03 & 0.05 & 0.17 & 0.16 \\
\hline $\begin{array}{l}\text { \# Paymt } \\
\text { Methods }\end{array}$ & & & & & & & & -- & 0.19 & 0.15 & 0.15 & 0.15 & 0.02 & 0.09 & 0.19 & 0.18 \\
\hline $\begin{array}{l}\text { \# Unique } \\
\text { Credit Crds }\end{array}$ & & & & & & & & & -- & 0.11 & 0.07 & 0.07 & 0.04 & 0.09 & 0.03 & 0.03 \\
\hline $\begin{array}{l}\text { Total } \\
\text { Withdl Amt }\end{array}$ & & & & & & & & & & -- & 0.58 & 0.57 & 0.39 & 0.90 & 0.08 & 0.03 \\
\hline \# Withdls & & & & & & & & & & & -- & 0.97 & 0.56 & 0.22 & 0.09 & 0.03 \\
\hline $\begin{array}{l}\text { \# Withdl } \\
\text { Days }\end{array}$ & & & & & & & & & & & & -- & 0.44 & 0.21 & 0.08 & 0.03 \\
\hline $\begin{array}{l}\text { Withdls per } \\
\text { Withdl Day }\end{array}$ & & & & & & & & & & & & & -- & 0.20 & -0.06 & -0.12 \\
\hline $\begin{array}{l}\text { Avg Withdl } \\
\text { Amt }\end{array}$ & & & & & & & & & & & & & & -- & -0.03 & -0.06 \\
\hline $\begin{array}{l}\text { \# Rvrsed } \\
\text { Withdls }\end{array}$ & & & & & & & & & & & & & & & -- & 0.99 \\
\hline $\begin{array}{l}\text { \% Revrsed } \\
\text { Withdls }\end{array}$ & & & & & & & & & & & & & & & & -- \\
\hline
\end{tabular}

a Unless stated otherwise, references to deposits and withdrawals indicate completed deposits and withdrawals (as opposed to including those that failed or were reversed). *Spearman correlations that are not significant at $p<0.001$ are flagged. 


\section{Highly Involved Sports Bettors - Research Question 3}

We examined whether there were subgroups of subscribers whose betting activity was disproportionately different from that of other subscribers by examining centile plots for total wagered, net loss, and number of bets, as presented in Figure 2a through 2c.

Figure 2a-c. Percentile Distributions for Total Wagered, Number of Bets, and Net Loss.
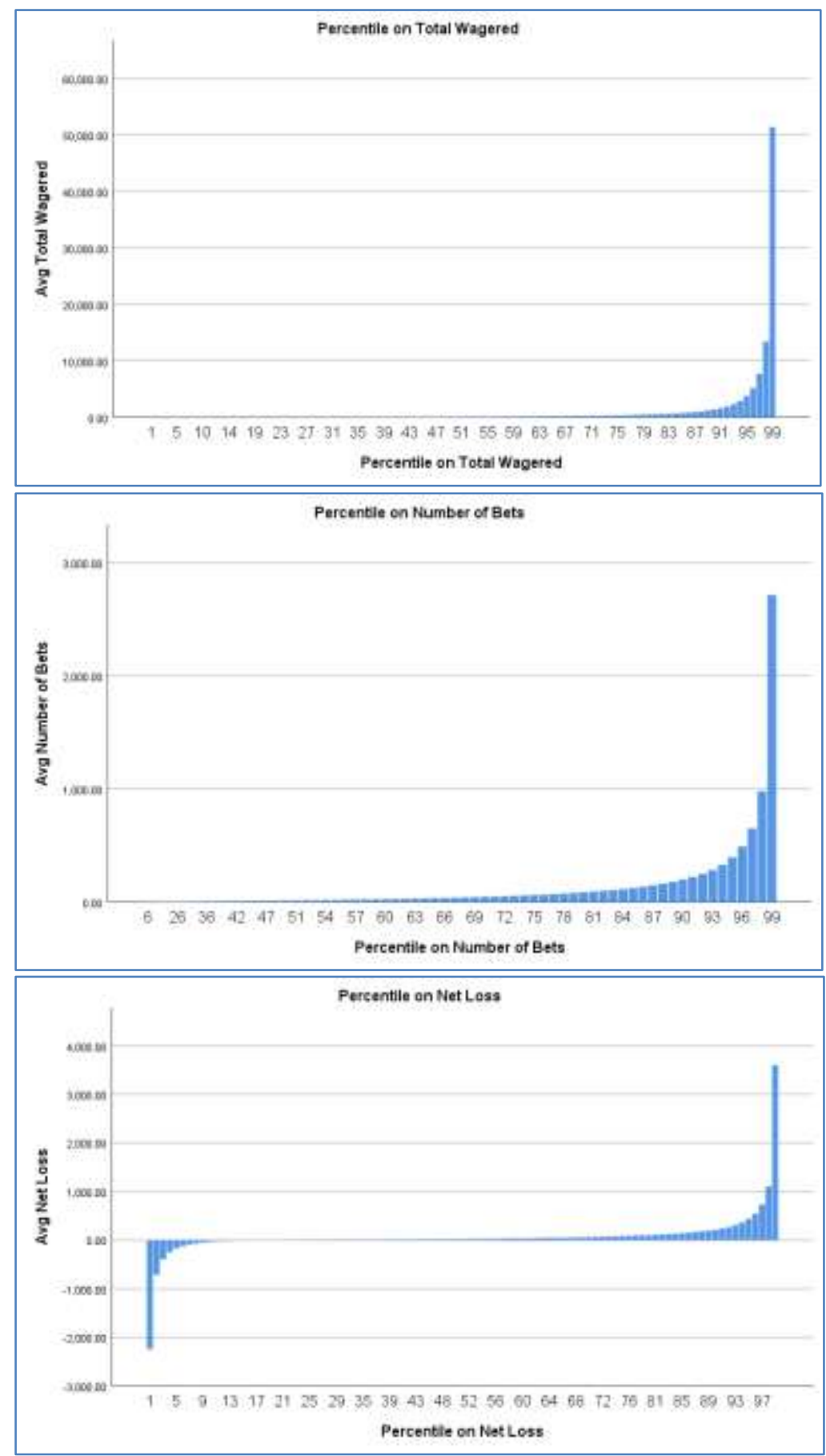

a For 13 bettors, none of their bets had yet resolved, so they are not included in the net loss percentile calculation; therefore, $n=32,249$ for this variable. 
As shown in the figure, there is clear discontinuity in at least the top $2 \%$ (though arguably in the top $3 \%$ for total wagered). To have comparably sized groups, we chose to distinguish the top $2 \%$ on each of the three variables. We designated each of these $2 \%$ groups as "Most Involved Bettors" (MIBs) on the given variable. ${ }^{5}$

Table 6 includes information about the overlap between these MIB groups. As the Table shows, more than $60 \%$ of the subscribers in the total wagered MIB group also belonged to another MIB group. Approximately half of the subscribers in the number of bets and net loss MIB groups also belonged to other MIB groups. The lowest overlap between MIB groups (10\%) was between the number of bets MIB group and the net loss MIB group. Overlap between the other groups was approximately $20 \%-22 \%$. One hundred twenty-two (8.9\%) of the 1,370 subscribers who belonged to at least one MIB group belonged to all three. Though these overlaps are considerable, Fisher's exact tests demonstrated that in all cases, MIB subscribers were more likely to belong to one MIB group than two (all Fisher's exact tests, $p<$ $0.001)$.

Table 6. Overlap between Top 2\% MIB Groups

\begin{tabular}{|c|c|c|c|c|c|c|c|}
\hline MIB Group & MIB $_{\text {Tw }}$ Only & $\mathrm{MIB}_{\mathrm{NB}}$ Only & $\mathrm{MIB}_{\mathrm{NL}}$ Only & $\mathrm{MIB}_{\text {TW\&NB }}$ & MIB $_{\text {TW\&NL }}$ & $\mathrm{MIB}_{\mathrm{NB} \& \mathrm{NL}}$ & $M^{\prime} B_{T W \& N B \& N L}$ \\
\hline $\begin{array}{l}\mathrm{MIB}_{\mathrm{TW}} \\
(n=651)\end{array}$ & 254 (39.0\%) & - & - & $131(20.1 \%)$ & $144(22.1 \%)$ & - & $122(18.7 \%)$ \\
\hline $\begin{array}{l}\mathrm{MIB}_{\mathrm{NB}} \\
(n=652)\end{array}$ & - & $334(51.2 \%)$ & - & $131(20.1 \%)$ & - & 65 (10.0\%) & $122(18.7 \%)$ \\
\hline $\begin{array}{l}\mathrm{MIB}_{\mathrm{NL}} \\
(n=651)\end{array}$ & - & - & $320(49.2 \%)$ & - & $144(22.1 \%)$ & 65 (10.0\%) & $122(18.7 \%)$ \\
\hline
\end{tabular}

$\mathrm{NL}=$ Net loss; $\mathrm{TW}=$ Total wagered; NB = Number of bets.

We compared subscribers who belonged to each of these MIB groups to subscribers who did not belong to any of these MIB groups (i.e., less-involved bettors: LIBs) on demographics and all betting behavior and transactional activity variables. Tables 7 and 8 display these comparisons. Subscribers in the MIB groups were older than other subscribers, less likely to reside in the UK or Germany, and more likely to reside in Spain or other countries accounting for fewer than $5 \%$ of subscribers. Subscribers in the MIB group for total wagered also were more likely to be female than other subscribers. 
Table 7. Median and Mean (SD) Betting and Transactional Behaviors by MIB Group

\begin{tabular}{|c|c|c|c|c|c|c|c|c|}
\hline \multirow[t]{2}{*}{ Variable } & \multicolumn{2}{|c|}{$\mathrm{MIB}_{\mathrm{TW}}(n=651)$} & \multicolumn{2}{|c|}{$\mathrm{MIB}_{\mathrm{NB}}(n=652)$} & \multicolumn{2}{|c|}{$\operatorname{MIB}_{N L}(n=651)$} & \multicolumn{2}{|c|}{$\operatorname{LIB}(n=30,892)^{\mathrm{e}}$} \\
\hline & Median & Mean (SD) & Median & Mean (SD) & Median & Mean (SD) & Median & Mean (SD) \\
\hline Duration & $121.00^{a}$ & $128.57(80.73)$ & $204.00^{b}$ & $168.71(0.59)$ & $193.00^{c}$ & $150.69(82.14)$ & $17.00^{a, b, c}$ & $58.67(77.10)$ \\
\hline Frequency & 56.88 & $57.40(26.94)$ & $59.40^{\mathrm{b}}$ & $59.14(22.97)$ & 41.23 & $46.52(26.63)$ & $45.00^{b}$ & $53.05(37.03)$ \\
\hline \# of Bets & $533.00^{a}$ & $\begin{array}{l}1130.15 \\
(1872.59) \\
\end{array}$ & $1,273.50^{b}$ & $\begin{array}{l}1845.92 \\
(1803.51)\end{array}$ & $326.00^{c}$ & $\begin{array}{l}850.48 \\
(1473.59) \\
\end{array}$ & $14.00^{a, b, c}$ & $51.72(96.79)$ \\
\hline In-game Bet \% & $96.77^{a}$ & $78.91(31.64)$ & $82.28^{b}$ & $65.35(36.51)$ & $68.75^{c}$ & $59.49(35.37)$ & $14.29 \mathrm{a}, \mathrm{b}, \mathrm{c}$ & $29.68(34.38)$ \\
\hline Combo Bet \% & $2.52^{\mathrm{a}}$ & $15.44(23.67)$ & $7.83^{b}$ & $22.16(28.19)$ & 30.92 & $36.77(32.15)$ & $26.78^{a, b}$ & $37.08(36.82)$ \\
\hline System Bet \% & 0.00 & $3.08(12.60)$ & $0.00^{\mathrm{b}}$ & $16.36(29.76)$ & $0.00^{c}$ & 7.55 (19.37) & $0.00^{b, c}$ & 4.44 (16.09) \\
\hline Bets per Betting Day & $12.88^{a}$ & $19.20(24.00)$ & $17.62^{b}$ & $25.18(25.04)$ & $7.54^{c}$ & $13.32(17.69)$ & $2.33^{a, b, c}$ & $3.81(4.67)$ \\
\hline Total Wagered & $18632.55^{a}$ & $\begin{array}{l}32378.86 \\
(40395.46)\end{array}$ & $6,338.14^{b}$ & $\begin{array}{l}20887.87 \\
(39911.61)\end{array}$ & $7,275.29^{c}$ & $\begin{array}{l}17496.45 \\
(33023.60)\end{array}$ & $96.62^{a, b, c}$ & $368.60(887.54)$ \\
\hline \# of Games Played & 1.00 & $1.28(0.52)$ & $1.00^{b}$ & $1.39(0.60)$ & $1.00^{c}$ & $1.45(0.62)$ & $1.00^{b, c}$ & $1.29(0.53)$ \\
\hline In-Game \% Wagered & $97.97^{a}$ & $79.91(31.77)$ & $84.00^{b}$ & $67.74(35.20)$ & $71.46^{c}$ & $60.68(35.85)$ & $13.16^{a, b, c}$ & $29.60(34.86)$ \\
\hline Combo \% Wagered & $1.30^{a}$ & $14.90(24.08)$ & $10.26^{b}$ & $22.95(27.56)$ & 31.20 & $37.25(32.84)$ & $25.98^{\mathrm{a}, \mathrm{b}}$ & 36.95 (37.05) \\
\hline System \% Wagered & 0.00 & $1.03(5.80)$ & $0.00^{\mathrm{b}}$ & $9.98(21.48)$ & $0.00^{c}$ & $3.16(11.09)$ & $0.00^{b, c}$ & $2.77(11.79)$ \\
\hline Average Bet Size & $43.46^{a}$ & 85.60 (136.07) & $4.28^{b}$ & $12.49(24.19)$ & $27.46^{c}$ & $63.64(108.41)$ & $5.93^{a, b, c}$ & $16.59(34.70)$ \\
\hline Net Loss & 302.59 & $797.92(3611.93)$ & $354.93^{b}$ & $\begin{array}{l}838.78 \\
(2788.49) \\
\end{array}$ & $1,397.00^{c}$ & $\begin{array}{l}2351.38 \\
(2636.35) \\
\end{array}$ & $23.72^{b, c}$ & $37.90(221.43)$ \\
\hline$\%$ Lost & $1.42^{a}$ & $2.62(12.58)$ & $8.33^{b}$ & $9.33(15.98)$ & $21.97^{c}$ & $29.75(23.49)$ & $38.08^{a, b, c}$ & $34.55(112.51)$ \\
\hline Total Deposit ${ }^{\mathrm{d}}$ Amount & $1,940.00^{a}$ & $\begin{array}{l}3766.15 \\
(5150.65) \\
\end{array}$ & $800.31^{b}$ & $\begin{array}{l}2227.29 \\
(4329.98) \\
\end{array}$ & $2,080.00^{c}$ & $\begin{array}{l}3720.97 \\
(4745.31)\end{array}$ & $48.00^{a, b, c}$ & $167.39(797.71)$ \\
\hline \# of Deposits & $18.00^{a}$ & $40.01(55.29)$ & $26.00^{b}$ & $44.94(57.06)$ & $37.00^{c}$ & $54.86(55.88)$ & $2.00^{a, b, c}$ & 4.59 (11.52) \\
\hline \# of Deposit Days & $12.00^{a}$ & $23.70(27.88)$ & $21.00^{\mathrm{b}}$ & $30.36(30.14)$ & $26.00^{c}$ & $33.73(29.34)$ & $1.00^{a, b, c}$ & $3.63(6.42)$ \\
\hline Deposits per Deposit Day & $1.35^{\mathrm{a}}$ & $1.60(0.87)$ & $1.15^{\mathrm{b}}$ & $1.32(0.49)$ & $1.39^{c}$ & $1.65(0.90)$ & $1.00^{a, b, c}$ & $1.13(0.44)$ \\
\hline Average Deposit Amount & $95.14^{\mathrm{a}}$ & $175.44(240.23)$ & $33.20^{b}$ & $67.62(113.17)$ & $69.05^{c}$ & $141.46(202.08)$ & $20.00^{a, b, c}$ & $38.39(80.20)$ \\
\hline \# of Failed Deposits & $3.00^{\mathrm{a}}$ & $13.55(26.54)$ & $4.00^{b}$ & $13.85(30.96)$ & $7.00^{c}$ & $18.79(31.54)$ & $0.00^{a, b, c}$ & $1.91(7.11)$ \\
\hline \% Failed Deposits & $14.29^{a}$ & $19.51(19.00)$ & $13.64^{b}$ & $18.92(18.40)$ & $16.67^{c}$ & $21.66(18.60)$ & $0.00^{a, b, c}$ & $17.41(25.19)$ \\
\hline \# of Payment Methods & $1.00^{\mathrm{a}}$ & $1.61(1.01)$ & $1.00^{\mathrm{b}}$ & $1.64(1.01)$ & $2.00^{c}$ & $1.90(1.19)$ & $1.00^{a, b, c}$ & $1.25(0.59)$ \\
\hline \# of Unique Credit Cards & $0.00^{a}$ & $0.35(0.56)$ & $0.00^{b}$ & $0.39(0.58)$ & $0.00^{c}$ & $0.47(0.58)$ & $0.00^{a, b, c}$ & $0.25(0.45)$ \\
\hline Total Withdrawal Amount & $1,913.97^{a}$ & $\begin{array}{l}3006.81 \\
(3545.91)\end{array}$ & $652.00^{b}$ & $\begin{array}{l}1688.83 \\
(2595.40) \\
\end{array}$ & $850.00^{c}$ & $\begin{array}{l}1753.74 \\
(2930.55) \\
\end{array}$ & $105.00^{a, b, c}$ & $\begin{array}{l}331.56 \\
(1042.60)\end{array}$ \\
\hline \# of Withdrawals & $5.00^{a}$ & 8.59 (14.03) & $4.00^{b}$ & $7.87(13.56)$ & $4.00^{c}$ & $7.99(15.00)$ & $1.00^{a, b, c}$ & $1.96(3.11)$ \\
\hline \# of Withdrawal Days & $4.00^{a}$ & $6.85(9.33)$ & $4.00^{b}$ & $6.59(9.15)$ & $3.00^{c}$ & $6.35(9.68)$ & $1.00^{a, b, c}$ & $1.82(2.48)$ \\
\hline Withdrawals per Withdrawal Day & $1.00^{\mathrm{a}}$ & $1.24(1.03)$ & $1.00^{\mathrm{b}}$ & $1.08(0.28)$ & $1.00^{c}$ & $1.07(0.39)$ & $1.00^{a, b, c}$ & $1.01(0.30)$ \\
\hline Average Withdrawal Amount & $356.56^{a}$ & $688.70(1020.78)$ & $151.17^{b}$ & $332.59(653.42)$ & $200.00^{c}$ & $322.94(408.06)$ & $73.52^{a, b, c}$ & $168.33(349.60)$ \\
\hline \# of Reversed Withdrawals & $0.00^{a}$ & $1.47(5.27)$ & $0.00^{\mathrm{b}}$ & $1.23(5.21)$ & $0.00^{c}$ & $1.53(5.46)$ & $0.00^{a, b, c}$ & $0.39(3.75)$ \\
\hline \% Reversed Withdrawals & $0.00^{a}$ & $10.77(21.83)$ & $0.00^{b}$ & $7.76(17.32)$ & $0.00^{c}$ & $14.23(26.60)$ & $0.00^{a, b, c}$ & $7.56(22.27)$ \\
\hline Age & $30.00^{a}$ & $32.76(11.03)$ & $33.00^{b}$ & $35.23(11.15)$ & $30.00^{c}$ & $32.17(9.92)$ & $27.00^{a, b, c}$ & $29.98(10.27)$ \\
\hline
\end{tabular}


Note. MIB groups are not exclusive - as noted in Table 6, some individuals belong to more than one MIB group.

a Significant difference between MIB $\mathrm{TW}_{\mathrm{T}}$ and LIB, $p<0.001$, according to Mann-Whitney $U$ Tests

b Significant difference between $\mathrm{MIB}_{\mathrm{NB}}$ and LIB, $p<0.001$, according to Mann-Whitney $U$ Tests

c Significant difference between MIB $\mathrm{NL}_{\mathrm{N}}$ and LIB, $p<0.001$, according to Mann-Whitney $U$ Tests

d Unless stated otherwise, references to deposits and withdrawals indicate completed deposits and withdrawals (as opposed to including those that failed or were reversed).

e For 13 bettors, none of their bets had yet resolved, so they are not included in analyses of the net loss or percent lost variables; therefore, $n=32,249$ for these variables, and $n$

for LIB for these variables $=30879$. Only 9,529 individuals in the sample placed withdrawals during the study period; therefore, $n=9,529$ for analyses that include withdrawal

variables ( $n$ for LIB for these variables $=8616 ; n$ for $\mathrm{MIB}_{\mathrm{TW}}$ for these variables $=539 ; n$ for $\mathrm{MIB}_{\mathrm{NB}}$ for these variables $=419 ; n$ for $\mathrm{MIB}_{\mathrm{NL}}$ for these variables $=387$ ).

Table 8. Count and Percentages for Demographic Variables and Betting and Transactional Behaviors by MIB Group

\begin{tabular}{|c|c|c|c|c|c|c|c|c|}
\hline \multirow{2}{*}{ Variable } & \multicolumn{2}{|c|}{$\mathrm{MIB}_{\mathrm{TW}}(\mathrm{n}=651)$} & \multicolumn{2}{|c|}{$\mathrm{MIB}_{\mathrm{NB}}(\mathrm{n}=652)$} & \multicolumn{2}{|c|}{$\operatorname{MIB}_{N L}(n=325)$} & \multicolumn{2}{|c|}{ LIB $(n=30892)$} \\
\hline & $\#$ & $\%$ & $\#$ & $\%$ & $\#$ & $\%$ & $\#$ & $\%$ \\
\hline $\begin{array}{c}\text { Gender }{ }^{a} \\
\text { Female } \\
\text { Male }\end{array}$ & $\begin{array}{l}92 \\
559\end{array}$ & $\begin{array}{l}14.1 \% \\
85.9 \%\end{array}$ & $\begin{array}{l}86 \\
566\end{array}$ & $\begin{array}{l}13.2 \% \\
86.8 \%\end{array}$ & $\begin{array}{l}59 \\
592\end{array}$ & $\begin{array}{l}9.1 \% \\
90.9 \%\end{array}$ & $\begin{array}{l}2860 \\
28,032\end{array}$ & $\begin{array}{l}9.3 \% \\
90.7 \%\end{array}$ \\
\hline $\begin{array}{l}\text { Country Group a,b,c,d } \\
\text { Germany } \\
\text { Spain } \\
\text { UK } \\
\text { France } \\
\text { Other Country }\end{array}$ & $\begin{array}{l}83 \\
160 \\
35 \\
75 \\
298 \\
\end{array}$ & $\begin{array}{l}12.7 \% \\
24.6 \% \\
5.4 \% \\
11.5 \% \\
45.8 \% \\
\end{array}$ & $\begin{array}{l}143 \\
167 \\
17 \\
72 \\
253 \\
\end{array}$ & $\begin{array}{l}21.9 \% \\
25.6 \% \\
2.6 \% \\
11.0 \% \\
38.8 \% \\
\end{array}$ & $\begin{array}{l}159 \\
137 \\
32 \\
141 \\
182 \\
\end{array}$ & $\begin{array}{l}24.4 \% \\
21.0 \% \\
4.9 \% \\
21.7 \% \\
28.0 \% \\
\end{array}$ & $\begin{array}{l}10,058 \\
5,093 \\
4,802 \\
3,471 \\
7,468\end{array}$ & $\begin{array}{l}32.6 \% \\
16.5 \% \\
15.5 \% \\
11.2 \% \\
24.2 \% \\
\end{array}$ \\
\hline Played 2+ Game Types b,c & 158 & $24.3 \%$ & 213 & $32.7 \%$ & 246 & $37.8 \%$ & 7,734 & $25.0 \%$ \\
\hline Placed Only Single Pre-Match Bets ${ }^{a, b, c}$ & 9 & $1.4 \%$ & 3 & $0.5 \%$ & 4 & $0.6 \%$ & 4,824 & $15.6 \%$ \\
\hline Placed Any In-Game Bets a,b,c & 639 & $98.2 \%$ & 645 & $98.9 \%$ & 632 & $97.1 \%$ & 19,797 & $64.1 \%$ \\
\hline Placed Any Combo Bets b,c & 441 & $67.7 \%$ & 552 & $84.7 \%$ & 587 & $90.2 \%$ & 24,421 & $69.3 \%$ \\
\hline Placed Any System Bets b,c & 93 & $14.3 \%$ & 281 & $43.1 \%$ & 184 & $28.3 \%$ & 3,435 & $11.1 \%$ \\
\hline Placed Any Failed Deposits ${ }^{a, b, c}$ & 497 & $76.3 \%$ & 526 & $80.7 \%$ & 582 & $89.4 \%$ & 12,623 & $40.9 \%$ \\
\hline Reversed Any Withdrawals $a, b, c, e$ & 171 & $31.7 \%$ & 107 & $25.5 \%$ & 136 & $35.1 \%$ & 1,138 & $13.2 \%$ \\
\hline
\end{tabular}

Note. MIB groups are not exclusive - as noted in Table 6, some individuals belong to more than one MIB group.

a Significant difference between MIB $\mathrm{TW}_{\mathrm{TW}}$ and LIB, $p<0.001$, according to Fisher's Exact Test

${ }^{b}$ Significant difference between MIB $_{\mathrm{NB}}$ and LIB, $p<0.001$, according to Fisher's Exact Test

c Significant difference between MIB ${ }_{N L}$ and LIB, $p<0.001$, according to Fisher's Exact Test

d For the analyses by country group, Fisher's Exact Test could not be used, so the Chi Square Test was employed instead.

e Only 9,529 individuals in the sample placed withdrawals during the study period; therefore, $n=9,529$ for analyses that include withdrawal variables ( $n$ for LIB for these

variables = 8,616; $n$ for $\mathrm{MIB}_{\mathrm{Tw}}$ for these variables $=539 ; n$ for $\mathrm{MIB}_{\mathrm{NB}}$ for these variables $=419 ; n$ for $\mathrm{MIB}_{\mathrm{NL}}$ for these variables $=387$ ). 
As the Tables show, subscribers in the MIB groups had significantly higher levels of betting and transactional activity than LIBs across all transactional activity variables and almost all betting activity variables. There are a few notable exceptions. Subscribers who were in the MIB groups for total wagered and net loss did not exhibit significantly greater frequency of betting than LIBs. Subscribers who were in the MIB group for total wagered also did not exhibit significantly greater net loss than LIBs and did not differ on number of games played. Subscribers who were in the number of bets MIB group had lower average bet sizes than LIBs. All MIB groups had significantly lower percent lost than other subscribers.

Though all MIB groups placed a greater percentage of their bets on in-game propositions than other subscribers, the difference for combo bet percentage was in the opposite direction for the total wagered and number of bets MIB groups (i.e., these MIB subscribers had a lower percentage of their bets that were combo bets than subscribers who weren't in MIB groups) and was not significant for the net loss MIB group. System bets were rare across the groups, but more common among those in the number of bets and net loss MIB groups. However, when examining whether subscribers had placed any combo, or system bets, we found that both the number of bets and net loss MIB groups had greater proportions of subscribers who had placed these types of bets than the group of subscribers who did not belong to any MIB groups.

\section{Exploratory Analysis - Highly Involved Net Winners}

Based on investigation of the net loss centile plot, we noticed that there was not only a discontinuous top $2 \%$ group for net loss, but also a discontinuous bottom $2 \%$ group. Therefore, these exploratory analyses replicate the most involved analyses for this group compared to a slightly altered LIB group $(n=30,508)$, redefined as subscribers who did not belong to any of the MIB groups including MIB on net winnings. Tables 9 and 10 display these comparisons.

Fifty-nine percent of subscribers in the net winnings MIB group did not belong to any other MIB group. One quarter (24.7\%) belonged to both the net winnings and total wagered MIB group, $13.7 \%$ belonged to all three MIB groups (i.e., net winnings, total wagered, and number of bets), and only $2.6 \%$ belonged to the net winnings MIB group and the number of bets MIB group.

As Tables 9 and 10 show, subscribers in the net winnings MIB groups were older, more likely to be female, less likely to reside in the UK or Germany, and more likely to reside in other countries accounting for fewer than $5 \%$ of subscribers than LIBs. 
Table 9. Median and Mean (SD) Betting and Transactional Behaviors by MIB Group (Net Winners vs. LIB)

\begin{tabular}{|c|c|c|c|c|}
\hline \multirow{2}{*}{ Variable } & \multicolumn{2}{|c|}{$\mathrm{MIB}_{\mathrm{NW}}(n=651)$} & \multicolumn{2}{|c|}{ LIB $(n=30508)$} \\
\hline & Median & Mean (SD) & Median & Mean (SD) \\
\hline \# of Games Played & 1.00 & $1.24(0.52)$ & 1.00 & $1.29(0.53)$ \\
\hline Duration * & 69.00 & $88.74(79.47)$ & 17.00 & 58.37 (76.99) \\
\hline Frequency & 51.51 & $54.38(32.27)$ & 45.45 & $53.13(37.07)$ \\
\hline \# of Bets * & 125.00 & $478.77(1306.18)$ & 14.00 & $51.09(96.11)$ \\
\hline In-game Bet \%* & 94.74 & $63.29(42.41)$ & 14.29 & $29.42(34.19)$ \\
\hline Combo Bet \% * & 0.92 & $21.36(32.96)$ & 27.06 & $37.17(36.82)$ \\
\hline System Bet \% & 0.00 & $3.00(13.68)$ & 0.00 & $4.45(16.12)$ \\
\hline Bets per Betting Day * & 6.75 & $12.36(19.81)$ & 2.33 & $3.78(4.65)$ \\
\hline Total Wagered * & 5729.81 & $15365.29(30650.43)$ & 93.39 & $337.74(794.82)$ \\
\hline In-Game \% Wagered * & 97.78 & $64.22(42.80)$ & 12.94 & $29.32(34.65)$ \\
\hline Combo \% Wagered * & 0.09 & $20.71(33.20)$ & 26.25 & $37.05(37.04)$ \\
\hline System \% Wagered & 0.00 & $1.53(8.36)$ & 0.00 & $2.79(11.83)$ \\
\hline Average Bet Size * & 47.67 & $87.75(136.32)$ & 5.83 & $15.82(32.20)$ \\
\hline Net Loss * & -1019.74 & $-1477.03(1369.08)$ & 24.55 & $52.94(128.63)$ \\
\hline$\%$ Lost $*$ & -21.23 & $-103.89(318.93)$ & 38.90 & $37.12(101.25)$ \\
\hline Total Deposit Amount * & 459.00 & $1307.36(2902.79)$ & 46.43 & $158.57(742.21)$ \\
\hline \# of Deposits * & 4.00 & $12.71(34.35)$ & 2.00 & $4.50(10.67)$ \\
\hline \# of Deposit Days * & 3.00 & $8.13(14.17)$ & 1.00 & $3.59(6.25)$ \\
\hline Deposits per Deposit Day * & 1.0 & $1.35(0.70)$ & 1.00 & $1.13(0.44)$ \\
\hline Average Deposit Amount * & 87.50 & $195.27(335.66)$ & 20.00 & $36.56(67.86)$ \\
\hline \# of Failed Deposits * & 1.00 & $4.03(13.12)$ & 0.00 & $1.87(6.93)$ \\
\hline \% Failed Deposits & 8.33 & $17.14(20.83)$ & 0.00 & $17.40(25.23)$ \\
\hline \# of Payment Methods * & 1.00 & $1.32(0.64)$ & 1.00 & $1.25(0.59)$ \\
\hline \# of Unique Credit Cards * & 0.00 & $0.18(0.42)$ & 0.00 & $0.25(0.45)$ \\
\hline Total Withdrawal Amount * & $1,607.34$ & 2519.12 (3062.69) & 100.00 & $266.86(876.56)$ \\
\hline \# of Withdrawals * & 2.00 & $4.53(6.90)$ & 1.00 & $1.90(2.85)$ \\
\hline \# of Withdrawal Days * & 2.00 & $3.95(5.64)$ & 1.00 & $1.77(2.25)$ \\
\hline Withdrawals per Withdrawal Day * & 1.00 & $1.22(1.06)$ & 1.00 & $1.00(0.27)$ \\
\hline Average Withdrawal Amount * & 605.61 & $963.57(1194.50)$ & 69.00 & $136.02(224.84)$ \\
\hline \# of Reversed Withdrawals * & 0.00 & $0.57(2.32)$ & 0.00 & $0.39(3.81)$ \\
\hline \% Reversed Withdrawals * & 0.00 & $6.94(17.74)$ & 0.00 & $7.58(22.41)$ \\
\hline Age $^{*}$ & 29.00 & $32.23(11.03)$ & 27.00 & $29.95(10.26)$ \\
\hline
\end{tabular}

Note. Unless stated otherwise, references to deposits and withdrawals indicate completed deposits and withdrawals (as opposed to including those that failed or were reversed). For these exploratory analyses, the LIB group is reduced by the

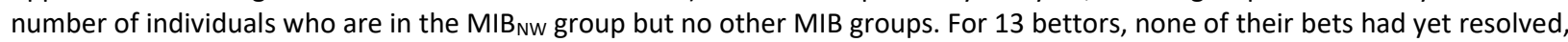
so they are not included in analyses of the net loss or percent lost variables; therefore, $n=32,249$ for these variables, and $n$ for LIB for these variables $=30,879$. Only 9,529 individuals in the sample placed withdrawals during the study period; therefore, $n=$ 9,529 for analyses that include withdrawal variables ( $n$ for LIB for these variables $=8,250$; $n$ for MIB $_{\mathrm{NW}}$ for these variables $=$ 618).

${ }^{*}$ Significant difference between $\mathrm{MIB}_{\mathrm{Nw}}$ and LIB, $p<0.001$, according to Mann-Whitney $U$ Tests

As with the other MIB groups, subscribers in the net winnings MIB group had significantly higher levels of betting and transactional activity than LIBs across almost all betting and transactional activity variables. Exceptions included number of games played, frequency, system bet percentage/percent wagered, and number of failed deposits, on which net winnings MIB subscribers did not differ from LIBs, as well as combo bet percentage/percent wagered, net loss, percent lost, and percent reversed withdrawals, on which net winnings MIB subscribers had lower scores than LIBs. 
Table 10. Count and Percentages for Demographic Variables and Betting and Transactional Behaviors by MIB Group (Net Winners vs. LIB)

\begin{tabular}{|l|l|l|l|l|}
\hline \hline \multirow{2}{*}{ Variable } & \multicolumn{2}{|c|}{ MIB $_{\text {NW }}(\mathrm{n}=651)$} & \multicolumn{2}{c|}{ LIB (n=30508) } \\
\cline { 2 - 5 } & \multicolumn{2}{|c|}{$\#$} & \multicolumn{2}{c|}{$\#$} \\
\hline $\begin{array}{l}\text { Gender * } \\
\text { Female }\end{array}$ & 109 & $16.7 \%$ & 2803 & $9.2 \%$ \\
Male & 542 & $83.3 \%$ & 27,705 & $90.8 \%$ \\
\hline Country Group a & & & & \\
Germany & 91 & $14.0 \%$ & 9,986 & $32.7 \%$ \\
Spain & 121 & $18.6 \%$ & 5,028 & $16.5 \%$ \\
UK & 51 & $7.8 \%$ & 4,764 & $15.6 \%$ \\
France & 38 & $5.8 \%$ & 3,437 & $11.3 \%$ \\
Other Country & 350 & $53.8 \%$ & 7,293 & $23.9 \%$ \\
\hline Played 2+ Game Types & 127 & $19.5 \%$ & 7,648 & $25.1 \%$ \\
\hline Placed Only Single Pre-Match Bets * & 37 & $5.7 \%$ & 4,793 & $15.7 \%$ \\
\hline Placed Any In-Game Bets * & 573 & $88.0 \%$ & 19,482 & $63.9 \%$ \\
\hline Placed Any Combo Bets * & 359 & $55.1 \%$ & 21,182 & $69.4 \%$ \\
\hline Placed Any System Bets & 56 & $8.6 \%$ & 3,396 & $11.1 \%$ \\
\hline Placed Any Failed Deposits * & 352 & $54.1 \%$ & 12,429 & $40.7 \%$ \\
\hline Reversed Any Withdrawals ${ }^{*}$ & 123 & $19.9 \%$ & 1,075 & $13.0 \%$ \\
\hline Significant difference between & & & \\
\hline
\end{tabular}

* Significant difference between $\mathrm{MIB}_{\mathrm{NW}}$ and LIB, $p<0.001$, according to Fisher's Exact Test

a For the analyses by country group, Fisher's Exact Test could not be used, so the Chi Square Test was employed instead.

${ }^{b}$ Only 9,529 individuals in the sample placed withdrawals during the study period; therefore, $n=9,529$ for analyses that include withdrawal variables ( $n$ for LIB for these variables $=8,250 ; n$ for MIB $_{N W}$ for these variables $=618$ ).

\section{Discussion}

This study examined the betting and transactional activity of a cohort of 32,262 sports wagering subscribers to a large online betting platform and compared that activity between small subgroups of subscribers who exhibited discontinuously high betting activity and the rest of the cohort. To facilitate a narrative comparison, these analyses largely replicated those conducted on a similar cohort of subscribers to the same platform ten years earlier (see LaBrie et al., 2007). The inclusion of transactional activity and multiple types of sports bets, as well as analyses that examine the betting and transactional activity of net winners represent an extension of this work.

\section{Key Findings - Overall Cohort Characteristics and Activity}

Demographically, the current cohort was very similar to that from ten years earlier - both were predominantly male (i.e., $91 \%$ in the current cohort and $92 \%$ in the earlier cohort) and had an average age of approximately 30 years old. Regional distribution was slightly different - though Germany was the most prevalent country of residence for both cohorts, the current cohort had many more subscribers from the UK, Spain, and France than the prior cohort. These regional differences likely relate to changes in the betting platform itself (e.g., bwin was acquired by GVC Holdings PLC, which has a wider customer base). 
As far as overall cohort betting behavior, findings were similar to those for the earlier cohort. Median bets per betting day, net loss, percent loss, and engagement with in-game betting were similar across cohorts - approximately 2.5 bets per betting day, 25 euros total lost, accounting for $36 \%$ of monies wagered, and 60-66\% engaging with in-game (previously called live action) betting. In fact, all betting variables that were measured in both studies were within the same order of magnitude, supporting Hypothesis 1 that the two cohorts would not differ in any fundamental way on their betting behavior. There were, however, a few minor differences between this cohort and the earlier cohort. Although we could not directly compare the cohorts statistically, the current cohort's median frequency of play (i.e., number of days on which they placed a bet, within their available duration), placing bets on close to half of the days available to them, was higher than the previous cohort, but their median duration (i.e., the number of days between their first and last bet within the study period, inclusive), less than a month, was shorter. The current cohort also made fewer overall bets, approximately 15 per subscriber, but wagered more per bet, a little over 6 euros.

For both cohorts, measures of gambling activity tended to be positively correlated. One exception was frequency, which was negatively correlated with duration in both cohorts, likely because individuals who placed only a handful of bets had a short duration and better chance of betting on $100 \%$ of the days within their duration. However, in the current cohort, but not the prior cohort, frequency was also negatively correlated with number of bets, total wagered, net loss, number of game types played, and betting on in-game, combo, and system propositions. Again, this is likely due to subscribers who only placed one or two bets on the platform, resulting in frequencies of $100 \%$ but low overall bets and total wagered. Number of bets also was inversely related to bet size in both cohorts - subscribers who placed more bets tended to place them for smaller amounts of money.

As hypothesized, the similarities between these two cohorts suggest that sports wagering behavior, at least on this platform, has remained relatively stable over time despite changes in the legislative and popular landscape. In both cohorts, the overall behavior of the sample can also arguably be described as modest to moderate. For example, if we consider the low-risk gambling limit recommendations of betting 8 days or less per month and wagering 75 Canadian dollars (i.e., approximately 48 euros) or less per month put forth by Currie and colleagues (see Currie et al., 2017), the current cohort's behavior falls within those limits. The median bettor bet on the site every other day (i.e., $46 \%$ of possible days) over a median duration of 19 days within the 8 month study period, which equates to 4 days per month. The median amount wagered of 100 euros, when divided over the 8 months of the study, equates to 12.5 euros per month. That said, during the duration they were active 
(i.e., the median 19 day duration), individuals in the current cohort were betting more frequently than advised by Currie and colleagues. In addition, our analyses of MIBs clearly indicate that a subset of individuals in our sample were gambling at levels well above those low-risk limits.

The minor differences that do exist, namely the shorter duration and the negative correlations between frequency and other metrics, suggest that the availability of more options for online sports wagering might be leading to a reduction in "stickiness" among consumers, with sports gamblers shopping around more for the best site or experience (see Xu \& Liu, 2010).

As noted above, two thirds of the current cohort had engaged in in-game betting during the study period; in the entire cohort, a median $16 \%$ of a subscriber's betting activity (and $15 \%$ of total wagered) was on in-game betting. Combo bets, often known as parlays, accounted for a median $26 \%$ of a subscriber's betting activity (and 15\% of total wagered); $70 \%$ of subscribers placed at least one combo bet during the study period. By contrast, only $12 \%$ placed a system bet (i.e., a combination of combo and single bets where only some of the bets need to be correct to win), and system bets accounted for a median $0 \%$ of subscribers betting activity (and $0 \%$ of total wagered). Most of the cohort engaged only in sports wagering. These findings suggest that among sports gamblers, utilization of multiple types of sports wagers is relatively common, but engaging in other types of gambling on this platform is not.

Transactional activity was minimal in the overall cohort. Subscribers made a median two deposits during the 8-month study period, totaling 50 euros across deposits. They made a median one withdrawal for a median 125 euros. Less than half of subscribers had any failed deposits, and $15 \%$ of subscribers reversed a withdrawal. Most subscribers used one payment method to make deposits, and did not use credit cards.

\section{Most Involved Bettors}

One of the greatest similarities between the current cohort of online sports gamblers and the cohort from a decade earlier is the discontinuity in their behavior. As can be seen clearly in Tables 2 and 4 , as well as Figure 2, there is a small handful of subscribers whose betting and transactional behavior is fundamentally different from the rest of the sample. For example, the maximum number of bets is 16,406 , even though the median number is 15 . This is also evident in transactional behavior, with a maximum total deposited of 50,315 euros despite a median deposit total of 50 euros. Consequently, we were able to distinguish groups of subscribers, each accounting for $2 \%$ of the study sample, whose behavior on total wagered, number of bets, and net loss, respectively, was notably different from the rest of the sample. Thus, Hypothesis 2 was supported. 
These most involved groups each represented $2 \%$ of our sample instead of the $1 \%$ identified by LaBrie et al. (2007). There are two possibilities for this difference. First, it is quite possible that the difference is not consequential and due instead to the error inherent in "eyeballing" the centile plot or random fluctuations. However, it is also possible that the proportion of subscribers who exhibit disproportionately high engagement with online sports gambling has increased in the past decade. This second possibility would be more likely if we had found that the MIB groups encompassed $5 \%$ of our sample, rather than just $2 \%$, since the difference between $5 \%$ and $1 \%$ is less easily explained by observer error than the difference between $2 \%$ and $1 \%$. We can, however, conclude that Hypothesis 3 , that $1 \%$ of the sample would fall into each MIB group, was basically supported: a very small percentage of the sample (i.e., $2 \%$ for each betting activity variable) had betting activity on total wagered, number of bets, and net loss that was disproportionately higher than the rest of the sample.

Hypothesis 4 predicted that the overlap between MIB groups for net loss and total wagered would be higher than the overlap between the MIB group for number of bets and either the net loss MIB group or total wagered MIB group. This hypothesis was not fully supported. The overlap between the number of bets MIB group and the total wagered MIB group (i.e., 20.1\%) was similar to that between the net loss and total wagered MIB groups (i.e., 22.1\%). However, there was less overlap between the number of bets and net loss MIB groups (i.e., 10.0\%). This suggests that those subscribers who lost the most money did so not through a disproportionately high number of bets but instead by placing especially large bets.

Comparison of gambling behaviors among these MIB groups and the LIB group revealed a few interesting findings. As observed in the prior LaBrie et al. (2007) study, though these subscribers' engagement was excessive in terms of financial and time involvement, their percent lost was less than other subscribers. In addition, the percent of their bets that were placed on combo bets, which might be considered the riskiest propositions for sports gamblers, was similar or lower than other subscribers. Those who were most involved in terms of money (i.e., total wagered and net loss) had similar frequencies of betting to other subscribers, and those who were most involved in terms of betting (i.e., number of bets), had lower average bet sizes than other subscribers. One common denominator among these top $2 \%$ groups was engagement with in-game betting. For each of these groups, in-game bets constituted a majority of their bets and amount wagered (97\%/98\% for the total wagered MIB group, $82 \% / 84 \%$ for the number of bets MIB group, and 69\%/71\% for the net loss MIB group), compared to only $14 \% / 13 \%$ for less involved bettors. Another common denominator is high levels of transactional activity and engagement in transactional behaviors that might be considered markers of risk, including 
failed deposits, reversed withdrawals, and unique payment methods. Finally, subscribers in the net loss and number of bets MIB groups were more likely than less involved subscribers to engage in online poker and/or casino gambling, but subscribers in the total wagered MIB group were not. Thus, Hypothesis 5, that MIB groups would be more likely than the LIB group to place combo, in-game, and system bets, and more likely to also play casino and poker, was partially supported. All of the highly involved subscribers were more engaged in-game betting than other subscribers, as predicted, and some highly involved groups were more likely to also be engaged in casino and/or poker, but these groups were less engaged in combo betting than other subscribers. (System betting was too rare in this cohort to draw any strong conclusions.)

These findings suggest a few things. First, these groups are deeply involved in sports betting, as evidenced by their activity, transactions, and participation in in-game betting. Second, these groups are possibly heterogeneous and should not be equated with gambling disorder or problematic play necessarily. These are very involved gamblers, but their percent loss is not high compared to other subscribers. That, coupled with the lack of combo betting, suggests that many of these bettors are experienced and potentially more savvy gamblers than others. Finally, groups defined by financial involvement and those defined by level of activity should not be equated. There was less overlap between the Number of bets MIB groups and other groups, suggesting that there is a distinct subgroup of players who spend very large amounts of time but might not be distinguishable by their financial involvement. This is important because many interventions use monetary metrics to identify subscribers who might be excessively involved; it is possible that some individuals who don't trigger those monetary flags might still be excessively involved or at risk of problems based on the time they spend (see Nelson et al., 2008).

In exploratory analyses, we also identified a group whose net winnings were disproportionately high compared to the rest of the sample. This group is important to examine because their winnings might be indicative of playing especially long odds, or experiencing at least one "big win", which some speculate can be a trigger for gambling problems (see Kassinove \& Schare, 2001; Turner, Zangeneh, \& Littman-Sharp, 2006). However, in our sample, this group looked similar to those in the Total wagered MIB group. They had very high monetary involvement, but their frequency of betting was not different from LIBs and they were less likely to engage in combo betting. Their in-game betting involvement was very high, with in-game betting accounting for a median 95\% of these subscribers' betting activity. Compared to other MIB groups, Net winners had a considerably shorter duration of play. The shorter duration and low frequency suggest the possibility that some of these subscribers might have hit it big 
but not continued playing after that. Alternatively, some of these individuals might be specialists in a particular sport, betting only during that sport's season, leading to shorter overall durations.

\section{Future Directions}

Additional research is needed to further investigate these groups of MIBs and determine their risk for gambling problems. As noted, there is possibly considerable heterogeneity within these MIB groups, with some subscribers at high risk for or experiencing gambling problems and others who prioritize gambling as a primary pastime but are gambling within their means and not experiencing problems. That research could include additional proxies for gambling problems (e.g., self exclusion), or combine behavioral data with surveys to screen for gambling problems.

In addition, future research needs to examine patterns of behavior across time. Prior work has shown that variability and failure to adapt are potential markers of harm among online gamblers (Braverman, LaPlante, Nelson, \& Shaffer, 2013; Braverman \& Shaffer, 2012; LaPlante, Schumann, LaBrie, \& Shaffer, 2008). A gambler who bets on sports at a stable level across time, even if that level is high, likely has different motivations and experiences than one who escalates his or her behavior or bets reactively.

Finally, more work needs to investigate different types of sports betting and ways in which subscribers engage with these types of bets across time. We found that in-game bets were very popular among MIBs, but combo betting was not. Combo betting is potentially the riskiest activity for sports gamblers because it involves longer odds than other bet types (see Golec \& Tamarkin, 1995). Further investigation of subscribers who engage with combo betting might yield additional insights about risky sports gambling behavior. In addition, examining the odds of the propositions subscribers choose and how that changes over time might also point to markers of potential problems.

\section{Limitations}

The current work has several limitations. First, though actual behavioral gambling data provides information that is more accurate and robust than self-report surveys, our ability to identify whether subscribers are experiencing problems is limited by the nature of these data. Without surveys or measures of income, it is difficult to determine whether a given level of play represents problematic play. Second, though our betting activity measures were specific to online sports gambling, our transactional activity variables (i.e., deposit and withdrawal information) were not. Therefore, if a subscriber engaged in sports wagering and other types of gambling on this platform, we were not able to determine what proportion of their deposit and withdrawal behavior was specific to online sports 
wagering. Finally, this work is constrained to a single platform. We were not able to account for subscribers' activity on other gambling platforms with other gambling operators.

\section{Conclusions}

This study provides a comprehensive investigation of online sports gambling behavior among a large cohort of subscribers to a major online gambling operator that specializes in sports gambling. Comparison to prior work from a decade ago suggests that the overall level of engagement within online sports gamblers has not changed substantially. Most subscribers engage at an arguably modest to moderate level, but a small subset can be distinguished whose engagement is disproportionately high. Transactional data reveals the same picture, with most subscribers engaging in few deposit and withdrawal behaviors while the most involved have greater transactional activity, including potential markers of risk such as failed deposits, reversed withdrawals, and multiple unique payment methods. Future research should delve deeper into individual sports wagering trajectories across time, as well as patterns of engagement with different types of sports gambling products, such as combo bets and ingame wagering. 


\section{References}

Blaszczynski, A., \& Hunt, C. (2011). Online sports betting has created new generation of problem gamblers. Retrieved from Sydney, NSW, Australia:

Braverman, J., LaPlante, D. A., Nelson, S. E., \& Shaffer, H. J. (2013). Using cross-game behavioral markers for early identification of high-risk Internet gamblers. Psychology of Addictive Behaviors, 27(3), 868-877.

Braverman, J., \& Shaffer, H. J. (2012). How do gamblers start gambling: Identifying behavioural markers for high-risk Internet gambling. European Journal of Public Health, 22(2), 273-278.

Braverman, J., Tom, M. A., \& Shaffer, H. J. (2014). Accuracy of self-reported versus actual online gambling wins and losses. Psychological Assessment, 26(3), 865-877. doi:10.1037/a0036428

Canale, N., Griffiths, M., Vieno, A., Siciliano, V., \& Molinaro, S. (2016). Impact of Internet gambling on problem gambling among adolescents in Italy: Findings from a large-scale nationally representative survey. Computers in Human Behavior, 57(C), 99-106.

Choliz, M. (2016). The challenge of online gambling: The effect of legalization on the increase in online gambling addiction. Journal of Gambling Studies, 32(2), 749-756. doi:10.1007/s10899-015-95586

Currie, S. R., Hodgins, D. C., Casey, D. M., El-Guebaly, N., Smith, G. J., Williams, R. J., \& Schopflocher, D. P. (2017). Deriving low-risk gambling limits from longitudinal data collected in two independent Canadian studies. Addiction, 112(11), 2011-2020. doi:10.1111/add.13909

Edson, T. C., \& LaPlante, D. A. (2020). Longitudinal playing trends among daily fantasy sports players. Computers in Human Behavior, 104, 106-165.

European Gaming and Betting Association. (2019). European Online Gambling Key Figures 2018. Retrieved from https://www.egba.eu/uploads/2019/12/European-Online-Gambling-KeyFigures-2018.pdf

Gainsbury, S. M. (2015). Online gambling addiction: The relationship between Internet gambling and disordered gambling. Current Addiction Reports, 2(2), 185-193. doi:10.1007/s40429-015-0057-8

Gainsbury, S. M., Angus, D. J., Procter, L., \& Blaszczynski, A. (2020). Use of consumer protection tools on Internet gambling sites: Customer perceptions, motivators, and barriers to use. Journal of Gambling Studies, 36(1), 259-276. doi:10.1007/s10899-019-09859-8

Golec, J., \& Tamarkin, M. (1995). Do bettors prefer long shots because they are risk-lovers, or are they just overconfident? Journal of Risk and Uncertainty, 11, 51-64.

Gray, H. M., Jonsson, G. K., LaPlante, D. A., \& Shaffer, H. J. (2015). Expanding the study of internet gambling behavior: Trends within the Icelandic lottery and sportsbetting platform. Journal of Gambling Studies, 31(2), 483-499. doi:10.1007/s10899-013-9427-0

Griffiths, M. D., \& Parke, J. (2002). The social impact of Internet gambling. Social Science Computer Review, 20(3), 312-320.

Kassinove, J. I., \& Schare, M. L. (2001). Effects of the "near miss" and the "big win" on persistence at slot machine gambling. Psychology of Addictive Behaviors, 15(2), 155-158.

LaBrie, R. A., Kaplan, S. A., LaPlante, D. A., Nelson, S. E., \& Shaffer, H. J. (2008). Inside the virtual casino: A prospective longitudinal study of Internet casino gambling. European Journal of Public Health, 18(4), 410-416.

LaBrie, R. A., LaPlante, D. A., Nelson, S. E., Schumann, A., \& Shaffer, H. J. (2007). Assessing the playing field: A prospective longitudinal study of internet sports gambling behavior. Journal of Gambling Studies, 23(3), 347-362. doi:10.1007/s10899-007-9067-3

Ladd, G. T., \& Petry, N. M. (2002). Disordered gambling among university-based medical and dental patients: A focus on Internet gambling. Psychology of Addictive Behaviors, 16(1), 76-79. 
Retrieved from \\Doaserver\doa\Library \& Archives\REPRINT LIBRARY\Disordered gambling among university-based medical and dental patients.pdf

LaPlante, D. A., Kleschinsky, J. H., LaBrie, R. A., Nelson, S. E., \& Shaffer, H. J. (2009). Sitting at the virtual poker table: A prospective epidemiological study of actual Internet poker gambling behavior. Computers in Human Behavior, 25(3), 711-717.

LaPlante, D. A., Schumann, A., LaBrie, R. A., \& Shaffer, H. J. (2008). Population trends in Internet sports gambling. Computers in Human Behavior, 24(5), 2399-2414. doi:10.1016/j.chb.2008.02.015

Lawn, S., Oster, C., Riley, B., Smith, D., Baigent, M., \& Rahamathulla, M. (2020). A literature review and gap analysis of emerging technologies and new trends in gambling. International Journal of Environmental Research and Public Health, 17(3), 744. doi:10.3390/ijerph17030744

Legal Sports Report. (2020). Legislative Tracker: Sports Betting. Retrieved from https://www.legalsportsreport.com/sportsbetting-bill-tracker/

Lopez-Gonzalez, H., Estévez, A., \& Griffiths, M. (2019). Internet-based structural characteristics of sports betting and problem gambling severity: Is there a relationship? International Journal of Mental Health and Addiction, 17(6), 1360-1373.

Mitka, M. (2001). Win or lose, Internet gambling stakes are high. Journal of the American Medical Association, 285(8), 1005.

Nelson, S. E., Edson, T. C., Singh, P., Tom, M., Martin, R. J., LaPlante, D. A., . . Shaffer, H. J. (2019). Patterns of daily fantasy sport play: Tackling the issues. Journal of Gambl Studies, 35(1), 181204. doi:10.1007/s10899-018-09817-w

Nelson, S. E., LaPlante, D. A., Peller, A. J., Schumann, A., LaBrie, R. A., \& Shaffer, H. J. (2008). Real limits in the virtual world: Self-limiting behavior of Internet gamblers. Journal of Gambling Studies, 24(4), 463-477. doi:10.1007/s10899-008-9106-8

Parke, A., \& Parke, J. (2019). Transformation of sports betting into a rapid and continuous gambling activity: A grounded theoretical investigation of problem sports betting in online settings. International Journal of Mental Health and Addiction, 17(6), 1340-1359.

Petry, N. M., \& Mallya, S. (2004). Gambling participation and problems among employees at a university health center. Journal of Gambling Studies, 20(2), 155-170.

Shaffer, H. J., Peller, A. J., LaPlante, D. A., Nelson, S. E., \& LaBrie, R. A. (2010). Toward a paradigm shift in Internet gambling research: From opinion and self-report to actual behavior. Addiction Research \& Theory, 18(3), 270-283.

Sharman, S., Murphy, R., Turner, J. J. D., \& Roberts, A. (2019). Trends and patterns in UK treatment seeking gamblers: 2000-2015. Addictive Behaviors, 89, 51-56. doi:10.1016/j.addbeh.2018.09.009

Turner, N. E., Zangeneh, M., \& Littman-Sharp, N. (2006). The experience of gambling and its role in problem gambling. International Gambling Studies, 6(2), 237-266.

Winters, K. C., \& Derevensky, J. L. (2019). A review of sports wagering: Prevalence, characteristics of sports bettors, and association with problem gambling. Journal of Gambling Issues, 43, 102-127.

Wohl, M. J., Davis, C. G., \& Hollingshead, S. J. (2017). How much have you won or lost? Personalized behavioral feedback about gambling expenditures regulates play. Computers in Human Behavior, 70, 437-445.

Xu, J., \& Liu, Z. (2010). Study of online stickiness: Its antecedents and effect on repurchase intention. Paper presented at the 2010 International Conference on e-Education, e-Business, eManagement and e-Learning. 


\section{Notes}

1 In-game bets refer to bets placed once a game has already begun. Combo bets refer to bets that include multiple single bets, all of which have to be correct to win. System bets refer to bets that include multiple single and/or combo bets, only some of which have to be correct to win.

2 This initial exclusion reduced the sample from 72,494 to 34,627, as Figure 1 shows. Most of those excluded did not place any bets during the study period. We do not know for certain why this was the case for such a large proportion of subscribers, but it is possible that these subscribers only placed promotional free bets which were not registered by the platform as actual bets because they did not involve actual money.

3 Pre-match bets were referred to as "fixed odds" bets, and in-game bets were referred to as "live action" bets in earlier publications (i.e., LaBrie et al., 2007).

4 Bet protection is a type of bet "insurance". Individuals can pay an additional amount when placing combo bets to "insure" some of their pre-match picks. Then, if these picks lose, leading to the loss of their combo bet, they still receive a partial refund for that bet.

5 In addition, for a later exploratory analysis, we also created a bottom $2 \%$ group for net loss because of the discontinuity at the bottom of the distribution. 


\section{Acknowledgements}

This manuscript was supported by a research contract between the Division on Addiction and GVC Holdings PLC. GVC is a large international gambling and online gambling operator. GVC had no involvement with the development of our research questions or protocol, the data collection/analysis, or development of this manuscript.

\section{Funding}

The Division on Addiction currently receives funding from the Addiction Treatment Center of New England via SAMHSA; EPIC Risk Management; The Foundation for Advancing Alcohol Responsibility (FAAR); DraftKings; the Gavin Foundation via the Substance Abuse and Mental Health Services Administration (SAMHSA); GVC Holdings, PLC; The Healing Lodge of the Seven Nations via the National Institutes of Health (National Institute of General Medical Sciences and National Institute on Drug Abuse); Health Resources in Action via the Massachusetts Department of Public Health Office of Problem Gambling Services; The Integrated Centre on Addiction Prevention and Treatment of the Tung Wah Group of Hospitals, Hong Kong; St. Francis House via the Massachusetts Department of Public Health Bureau of Substance Addiction Services; and the University of Nevada, Las Vegas via MGM Resorts International.

During the past 5 years, the Division on Addiction has also received funding from Aarhus University Hospital with funds approved by The Danish Council for Independent Research; ABMRF - The Foundation for Alcohol Research; Caesars Enterprise Services, LLC; the David H. Bor Library Fund, Cambridge Health Alliance; DraftKings; Fenway Community Health Center, Inc.; Massachusetts Department of Public Health, Bureau of Substance Addiction Services; Massachusetts Gaming Commission, Commonwealth of Massachusetts; and University of Nevada, Las Vegas via MGM Resorts International. 


\section{Supplementary Gender and Age Analyses of Betting and Transactional Activity}

In planned exploratory analyses, we examined whether subscribers' betting, deposit, or withdrawal activity differed by age or gender, using Spearman correlations and Mann-Whitney U tests, respectively.

As displayed in Table S1, we found significant Spearman correlations $(p<0.001)$ between age and eleven of the betting activity variables. Older subscribers had greater duration [Spearman's $\rho=$ $0.05]$, number of bets $[\rho=0.05]$, bets per betting day $[\rho=0.02]$, total wagered $[\rho=0.13]$, average bet size $[\rho=0.10]$, and net loss $[\rho=0.09]$, as well as a greater system bet percentage $[\rho=0.03]$ and system bet percent wagered $[\rho=0.03]$. Younger subscribers had a greater combo bet percentage $[\rho=-0.13]$ and combo bet percent wagered [ $\rho=-0.12$ ], as well as number of game types played [ $\rho=-0.08]$. Effect sizes were small; only the correlations between age and combo bet variables and age and total wagered were greater than 0.10. Frequency, in-game bet percentage, in-game percent wagered, and percent lost did not vary by age.

Table S1. Spearman Correlations between Age and Betting Behaviors $\left(\mathrm{N}=32,262^{\mathrm{a}}\right)$

\begin{tabular}{|l|l|}
\hline \hline Variable & Age \\
\hline Duration & $0.05^{*}$ \\
\hline Frequency & -0.02 \\
\hline \# of Bets & $0.05^{*}$ \\
\hline In-game Bet \% & -0.02 \\
\hline Combo Bet \% & $-0.13^{*}$ \\
\hline System Bet \% & $0.03^{*}$ \\
\hline Bets per Betting Day & $0.02^{*}$ \\
\hline Total Wagered & $0.13^{*}$ \\
\hline In-Game \% Wagered & -0.02 \\
\hline Combo \% Wagered & $-0.12^{*}$ \\
\hline System \% Wagered & $0.03^{*}$ \\
\hline Average Bet Size & $0.10^{*}$ \\
\hline Net Loss & $0.09^{*}$ \\
\hline \% Lost & -0.01 \\
\hline \# of Games Played & $-0.08^{*}$ \\
\hline
\end{tabular}

${ }^{a}$ For 13 bettors, none of their bets had yet resolved, so they are not included in the correlations with net loss or percent lost $n=32,249$ for correlations with these two variables. *Spearman correlations that are significant at $p<0.001$ are flagged.

As displayed in Table S2, we also found significant Spearman correlations $(p<0.001)$ between age and eight of the deposit activity variables and two of the withdrawal activity variables. Older subscribers had greater total deposit amounts [Spearman's $\rho=0.15]$, number of deposits [ $\rho=0.04$ ], number of deposit days [ $\rho=.04]$, average deposit amount $[\rho=0.20]$, and number of unique credit cards $[\rho$ $=0.07]$. Younger subscribers had a greater number of failed deposits $[\rho=-0.02]$ and percent failed 
deposits [ $\rho=-0.03$ ]. Effect sizes were small; only the correlations between age and total deposit amount and age and average deposit amount were greater than .10. Deposits per deposit day, and number of payment methods did not vary by age. Older subscribers also had greater total withdrawal amount $[\rho=$ $0.15]$ and average withdrawal amount $[\rho=0.18]$. Number of withdrawals, number of withdrawal days, withdrawals per withdrawal day, number of reversed withdrawals, and percent reversed withdrawals did not vary by age.

Table S2. Spearman Correlations between Age and Transactional Behaviors ( $N=32,262$ for deposit variables; $\mathrm{N}=9,529$ for withdrawal variables)

\begin{tabular}{|l|c|}
\hline \hline Variable & Age \\
\hline Total Deposit ${ }^{\text {a }}$ Amount & $0.15^{*}$ \\
\hline \# of Deposits & $0.04^{*}$ \\
\hline \# of Deposit Days & $0.04^{*}$ \\
\hline Deposits per Deposit Day & 0.01 \\
\hline Average Deposit Amount & $0.20^{*}$ \\
\hline \# of Failed Deposits & $-0.02^{*}$ \\
\hline \% Failed Deposits & $-0.03^{*}$ \\
\hline \# of Payment Methods & $-0.00^{*}$ \\
\hline \# of Unique Credit Cards & $0.07^{*}$ \\
\hline Total Withdrawal Amount & $0.15^{*}$ \\
\hline \# of Withdrawals & 0.01 \\
\hline \# of Withdrawal Days & 0.01 \\
\hline Withdrawals per Withdrawal Day & 0.00 \\
\hline Average Withdrawal Amount & $0.18^{*}$ \\
\hline \# of Reversed Withdrawals & -0.01 \\
\hline \% Reversed Withdrawals & -0.01 \\
\hline
\end{tabular}

a Unless stated otherwise, references to deposits and withdrawals indicate completed deposits and withdrawals (as opposed to including those that failed or were reversed). *Spearman correlations that are significant at $p<0.001$ are flagged.

As displayed in Table S3, nine betting activity variables differed significantly $(p<0.001)$ by gender. Men had greater duration of play $\left[\right.$ Median $_{M}=20$, Median $\left._{W}=13, U=39,678,377.5\right]$, number of bets $\left[\right.$ Median $_{M}=16$, Median $\left._{W}=11, U=40,931,120.0\right]$, and net loss $\left[\right.$ Median $_{M}=25$, Median $_{W}=20, U=$ $41,990,655.5$ ] than women, as well as higher combo bet percentages [Median $n_{M}=28 \%$, Median $=11 \%, U$ $=38,989,744.0]$, combo percent wagered Median $_{M}=27 \%$, Median $\left._{W}=10 \%, U=38,844,726.0\right]$, system bet percentages ${ }^{1}\left[\right.$ Median $_{M}=0 \%$, Median $\left._{W}=0 \%, U=43,207,769.5\right]$, and system percent wagered $\left[\right.$ Median $_{M}=0 \%$, Median $\left._{W}=0 \%, U=43,214,814.0\right]$.

\footnotetext{
${ }^{1}$ For system bet percentage, system percent wagered, number of deposits, number of unique credit cards, median behavior for men and women appeared identical, but men had slightly higher means on these variables than women (effect size $r=-0.02$ to -0.03 ). For number of payment methods, median behavior for men and women appeared identical, but women had slightly higher means on this variable than men (effect size $r=-0.02$ ).
} 
Table S3. Betting Behaviors by Gender $\left(\mathrm{N}=32,262^{\mathrm{a}}\right)$

\begin{tabular}{|c|c|c|c|c|c|c|c|c|}
\hline \multirow[b]{2}{*}{ Variable } & \multicolumn{3}{|c|}{ Male } & \multicolumn{3}{|c|}{ Female } & \multirow[b]{2}{*}{$\mathbf{U}$} & \multirow[b]{2}{*}{$r$ (effect size) } \\
\hline & Mean & SD & Median & Mean & SD & Median & & \\
\hline Duration & 63.44 & 79.65 & 20.00 & 50.65 & 72.84 & 13.00 & $39678377.50 *$ & -0.05 \\
\hline Frequency & 0.53 & 0.37 & 0.44 & 0.58 & 0.37 & 0.57 & 47661336.50* & 0.04 \\
\hline \# of Bets & 90.92 & 344.94 & 16.00 & 110.94 & 585.49 & 11.00 & $40931120.00 *$ & -0.04 \\
\hline In-game Bet \% & 0.31 & 0.35 & 0.17 & 0.33 & 0.39 & 0.14 & 44092982.50 & -0.00 \\
\hline Combo Bet \% & 0.37 & 0.37 & 0.28 & 0.31 & 0.37 & 0.11 & $38989744.00 *$ & -0.06 \\
\hline System Bet \% & 0.05 & 0.17 & 0.00 & 0.04 & 0.15 & 0.00 & $43207769.50 *$ & -0.02 \\
\hline Bets per Betting Day & 4.33 & 6.61 & 2.50 & 4.80 & 7.86 & 2.43 & 43692443.00 & -0.01 \\
\hline Total Wagered & $1,041.33$ & $6,829.40$ & 100.00 & $1,602.35$ & $11,271.25$ & 109.71 & 45221584.00 & 0.01 \\
\hline In-Game \% Wagered & 0.31 & 0.35 & 0.15 & 0.33 & 0.39 & 0.12 & 44051813.00 & -0.00 \\
\hline Combo \% Wagered & 0.37 & 0.37 & 0.27 & 0.31 & 0.37 & 0.10 & $38844726.00 *$ & -0.06 \\
\hline System \% Wagered & 0.03 & 0.12 & 0.00 & 0.03 & 0.12 & 0.00 & 43214814.00* & -0.02 \\
\hline Average Bet Size & 17.44 & 41.38 & 6.00 & 26.57 & 47.18 & 7.81 & $49059222.00 *$ & 0.06 \\
\hline Net Loss & 73.27 & 569.57 & 25.00 & 53.74 & 767.08 & 20.00 & 41990655.50* & -0.02 \\
\hline$\%$ Lost & 0.35 & 0.80 & 0.36 & 0.24 & 2.62 & 0.34 & 42901315.50 & -0.01 \\
\hline \# of Games Played & 1.30 & 0.54 & 1.00 & 1.26 & 0.52 & 1.00 & 42913138.50 & -0.02 \\
\hline
\end{tabular}

*Significant gender difference according to Mann-Whitney $U$ Test, $p<0.001 . r$ is the standardized test statistic divided by the square root of $\mathrm{N}$.

a For 13 bettors, none of their bets had yet resolved, so they are not included in the descriptives for net loss or percent lost - $\mathrm{n}=32,249$ for these two variables. 
Women had greater frequency of play [Median ${ }_{M}=44 \%$, Median $_{W}=57 \%, U=47,661,336.5$ ] and average bet size [Median $n_{M}=6.0$, Median ${ }_{W}=7.8, U=49,059,222.0$ ] than men. Effect sizes, as assessed by $r$, the standardized test statistic divided by the square root of $\mathrm{N}$, were small, ranging from -0.02 to 0.06 . As displayed in Table S4, five deposit activity variables and two withdrawal activity variables differed significantly $(\mathrm{p}<.001)$ by gender. Men had greater number of deposits [Median $\mathrm{n}_{\mathrm{M}}=2.0$, Median $_{W}=2.0, U=$ 42,362,148.5], number of deposit days [Median ${ }_{M}=2.0$, Median $\left._{W}=1.0, U=41,891,355.0\right]$, and number of unique credit cards $\left[\right.$ Median $_{M}=0.0$, Median $\left._{W}=0.0, U=42,371,289.0\right]$ than women. Women had greater average deposit amount $\left[\right.$ Median $_{M}=20.0$, Median $_{W}=21.3, U=47,270,002.0$ ] and number of payment

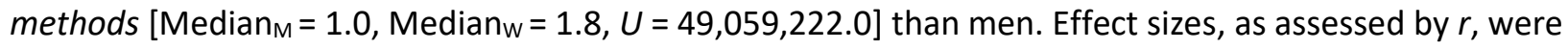
small, ranging from -0.03 to 0.06 . Women also had a greater total withdrawal amount [Median $\mathrm{M}_{\mathrm{M}}=120.0$, Median $_{W}=175.25, U=4,884,828.5$ ] and average withdrawal amount [Median $n_{M}=78.61$, Median $=$ $116.5, U=5,032,749.5]$. Effect sizes, as assessed by $r$, were small, ranging from 0.06 to 0.08 . 
Table S4. Transactional Behaviors by Gender ( $N=32,262$ for deposit variables; $N=9,529$ for withdrawal variables)

\begin{tabular}{|c|c|c|c|c|c|c|c|c|}
\hline & \multicolumn{3}{|c|}{ Male } & \multicolumn{3}{|c|}{ Female } & \multirow[b]{2}{*}{$U$} & \multirow[b]{2}{*}{$r$ (effect size) } \\
\hline Variable & Mean & SD & Median & Mean & SD & Median & & \\
\hline $\begin{array}{l}\text { Total Deposit } \\
\text { Amount } \\
\end{array}$ & 264.65 & 1197.34 & 50.00 & 280.73 & 1385.23 & 50.00 & 45370005.50 & 0.01 \\
\hline \# of Deposits & 6.02 & 16.29 & 2.00 & 5.98 & 18.79 & 2.00 & $42362148.50 *$ & -0.02 \\
\hline \# of Deposit Days & 4.56 & 9.32 & 2.00 & 4.32 & 9.71 & 1.00 & 41891355.00* & -0.03 \\
\hline $\begin{array}{l}\text { Deposits per Deposit } \\
\text { Day }\end{array}$ & 1.14 & 0.46 & 1.00 & 1.16 & 0.45 & 1.00 & 44490197.00 & 0.01 \\
\hline $\begin{array}{l}\text { Average Deposit } \\
\text { Amount }\end{array}$ & 41.51 & 91.61 & 20.00 & 48.90 & 85.49 & 21.33 & 47270002.00* & 0.04 \\
\hline \# of Failed Deposits & 2.35 & 9.10 & 0.00 & 2.42 & 8.31 & 0.00 & 43771937.00 & -0.01 \\
\hline \% Failed Deposits & 0.17 & 0.25 & 0.00 & 0.18 & 0.26 & 0.00 & 43978854.00 & -0.00 \\
\hline $\begin{array}{l}\text { \# of Payment } \\
\text { Methods }\end{array}$ & 1.26 & 0.61 & 1.00 & 1.30 & 0.67 & 1.00 & 45402198.00* & 0.02 \\
\hline $\begin{array}{l}\text { \# of Unique Credit } \\
\text { Cards }\end{array}$ & 0.26 & 0.46 & 0.00 & 0.22 & 0.44 & 0.00 & 42371289.00* & -0.03 \\
\hline $\begin{array}{l}\text { Total Withdrawal } \\
\text { Amount }\end{array}$ & 489.18 & 1485.40 & 120.00 & 545.43 & 1166.14 & 175.25 & $4884828.00^{*}$ & 0.06 \\
\hline \# of Withdrawals & 2.46 & 5.03 & 1.00 & 2.26 & 3.60 & 1.00 & 4272172.00 & -0.02 \\
\hline \# of Withdrawal Days & 2.20 & 3.63 & 1.00 & 2.13 & 3.29 & 1.00 & 4284349.00 & -0.01 \\
\hline $\begin{array}{l}\text { Withdrawals per } \\
\text { Withdrawal Day }\end{array}$ & 1.03 & 0.40 & 1.00 & 1.01 & 0.29 & 1.00 & 4303513.50 & -0.02 \\
\hline $\begin{array}{l}\text { Average Withdrawal } \\
\text { Amount }\end{array}$ & 193.19 & 430.92 & 78.61 & 252.89 & 446.73 & 116.50 & $5032749.50 *$ & 0.08 \\
\hline $\begin{array}{l}\text { \# of Reversed } \\
\text { Withdrawals }\end{array}$ & 0.47 & 4.00 & 0.00 & 0.42 & 1.77 & 0.00 & 4423515.00 & 0.01 \\
\hline $\begin{array}{l}\text { \% Reversed } \\
\text { Withdrawals }\end{array}$ & 0.08 & 0.22 & 0.00 & 0.08 & 0.23 & 0.00 & 4423201.00 & 0.01 \\
\hline
\end{tabular}

a Unless stated otherwise, references to deposits and withdrawals indicate completed deposits and withdrawals (as opposed to including those that failed or were reversed).

*Significant gender difference according to Mann-Whitney $U$ Test, $p<.001 . r$ is the standardized test statistic divided by the square root of $N$. 